\title{
Dimensões latentes da competitividade da micro e pequena indústria de transformação no Brasil: uma análise multivariada para o estado de Minas Gerais
}

\author{
Flávio de Oliveira Gonçalves* \\ Marco Túlio Aniceto França** \\ Rodrigo Gomes Marques Silvestre ${ }^{* * *}$
}

\begin{abstract}
Resumo: O presente artigo apresenta uma análise das dimensões latentes da competitividade nas micro e pequenas empresas da indústria de transformação no estado de Minas Gerais, Brasil. Utiliza-se a análise fatorial com a extração das componentes principais a partir de dados primários e secundários como forma de determinar estas dimensões. Os principais resultados apontam para a grande importância da participação no comércio internacional, seja como exportador ou mesmo ao importar máquinas, equipamentos e insumos. O componente local também está presente ao serem identificadas dimensões ligadas à infraestrutura, qualidade da mão-de-obra básica e de nível superior. Um papel menor foi identificado nas dimensões ligadas às estratégias e gestão das empresas, o que pode também refletir um problema de seleção - empresas de melhor gestão crescem e saem do universo de análise.
\end{abstract}

Palavras-chave: Competitividade; Micro e Pequena Indústria; Desenvolvimento; Análise Fatorial.

Classificação JEL: C02; L22; O12.

\footnotetext{
* Doutor em Economia pela Universidade de Brasília (UNB). Professor do Departamento de Economia da Universidade Federal do Paraná (UFPR). Endereço eletrônico: f.goncalves@ufpr.br

** Doutor em Desenvolvimento Econômico pela Universidade Federal do Paraná (UFPR). Assessor técnico na Secretaria da Familia e do Desenvolvimento Social (SEDS) do Estado do Paraná e professor na Fundacão Itau Social. Endereço eletrônico: tulio_franca@yahoo.com

*** Mestre em Desenvolvimento Econômico pela Universidade Federal do Paraná (UFPR). Economista na Kerygma Assessoria e Treinamento. Endereço eletrônico: silvestre@kerygmabrasil.com.br
} 


\section{Introdução}

Com a consolidação das conquistas macroeconômicas obtidas pelo Brasil nas décadas recentes (relativa estabilidade cambial e controle inflacionário), as atenções passaram a se voltar para a competitividade das empresas como fonte de desenvolvimento. A Pesquisa Anual de Comércio e a Pesquisa Anual de Serviços, em 2001, estimaram um total de 2 milhões de micro e pequenas empresas de comércio e serviços em operação no País, que ocupavam cerca de 7,3 milhões de pessoas, ou seja, 9,7\% da População Ocupada. Essas empresas geraram $\mathrm{R} \$ 168,2$ bilhões em receita operacional líquida e $\mathrm{R} \$ 61,8$ bilhões em valor adicionado (IBGE, 2001). Assim, torna-se premente melhorar a compreensão sobre os fatores que fundamentam a competitividade das empresas, em particular, daquelas de Micro e Pequeno Porte.

A compreensão da importância da competitividade, não é o mesmo que solucionar o problema de complexidade relacionado com sua análise. Isso significa que inúmeros esforços ainda serão necessários para explicitar integralmente os fatores latentes que tornam as empresas diferentes quando competem no mercado. Contribuir para essa discussão e somar conhecimento ao repositório coletivo são os principais motivadores do presente artigo. Além disso, uma segunda contribuição corresponde ao uso de dados primários, pois possibilita dar uma perspectiva analítica ao rol disponível na literatura econômica.

A presente pesquisa teve como estratégia empírica a construção das dimensões latentes da competitividade por meio da análise de componente principal de dados primários coletados de 800 observações de micro e pequenas empresas brasileiras. Os resultados foram sistematizados e apresentados, contribuindo para a compreensão sobre os fatores latentes da competitividade. Observamos que a principal variável latente para explicar a competitividade corresponde à participação no comércio internacional, seguida pela oferta de infraestrutura local. Existem outros fatores importantes como a qualificação da mão de obra básica e de nível superior que não estão relacionados diretamente à estrutura industrial. Todavia, a existência de planos estruturados e a atribuição de responsabilidades para sócios e empresários dizem respeito exclusivamente a estrutura produtiva.

$\mathrm{O}$ artigo se divide em seis partes, incluindo essa introdução. A seção 2 traz as referências para fundamentar o conceito de competitividade utilizado e discutir a noção de capacidades dinâmicas. A seção 3 apresenta a estratégia empírica e a base de dados utilizada. A seção 4 apresenta os resultados. $\mathrm{Na}$ seção 5, faremos as considerações finais e, posteriormente, as referências bibliográficas. 


\section{Referencial teórico}

Inicialmente pode-se considerar que a competitividade é um fenômeno mais pertinente às firmas que aos países. Krugman (1996) apresenta que grande parte do debate sobre o tema da competitividade ao nível nacional tratase, na verdade, de uma discussão sobre comércio internacional. De acordo com o autor, é falaciosa a ideia de que a competitividade entre as nações ocorre pela analogia da competitividade entre as firmas. Ou seja, o que define se uma nação é ou não "competitiva" no cenário internacional não é a sua dotação de recursos, tecnologia ou a simples soma da ação de suas empresas. Isto é, existem elementos associados a vantagens comparativas, culturais, etc.

É com base nesse argumento que o presente artigo busca um foco mais local da competitividade. A ideia é trazer à baila as dimensões regionais da competitividade, desta forma, permitindo contornar a discussão sobre comércio internacional, tanto do ponto de vista político quanto econômico. Esses fatos, dotados de seu interesse, não serão objeto do presente artigo. Entretanto, cabe destacar que as variáveis relacionadas ao comércio internacional não serão excluídas da análise.

Mais recentemente, a literatura reconhece como principal aspecto relacionado com a competitividade o conhecimento, em especial, aquele que é gerado e aplicado à produção. A competitividade associada a esse elemento tem fundamental importância quando se relaciona à dimensão regional da competitividade. Segundo Maskel e Malmberg (1999), a proximidade entre os atores, a espacialidade das relações de transação e as instituições locais são elementos cruciais para determinar a competitividade das empresas. Isso ocorre porque com o aumento da complexidade da tecnologia e dos produtos, a proximidade entre demandantes e ofertantes facilita o fluxo de conhecimento e aumenta a competitividade do conjunto de empresas.

Competitividade é função da adequação das estratégias das empresas individuais ao padrão de concorrência vigente no mercado específico. Kupfer (1992) destaca que, em cada mercado vigoraria um dado padrão de concorrência definido a partir da interação entre estrutura e condutas dominantes no setor. As firmas competitivas seriam aquelas que a cada instante adotam estratégias de conduta (investimentos, inovação, vendas, compras, financiamento, etc..) mais adequadas ao padrão de concorrência setorial. Portanto, a competitividade é um fenômeno "ex-post" que, porém, não é captado pelo desempenho corrente da firma no mercado. A competitividade da empresa no passado é também um determinante do seu desempenho no mercado atual. Entre esse momento passado e o presente, diferentes firmas, possivelmente, adotaram novas e diferentes estratégias, com base em expectativas incertas de retorno. $\mathrm{O}$ autor destaca que o problema central é como conhecer o padrão de concorrência vigente no mercado específico, inclusive no caso particular, em que o padrão parece estável, posto que não se possa ter certeza quanto a sua permanência 
Por essa razão, a conclusão a que se pode chegar a respeito da competitividade é a virtual impossibilidade de avaliá-la "ex-ante" de forma inequívoca. É possível, no entanto, por meio de estudos prospectivos, mapear expectativas dos agentes econômicos quanto à mudança do padrão de concorrência em um futuro determinado e utilizá-las como guia para avaliação da adequação das estratégias adotadas no presente pelas empresas. Se essas expectativas mostrarem-se convencionais (convergentes) dispor-se-á de um critério aceitável de avaliação de competitividade e de atuação sobre ela. O problema resume-se à construção de taxonomias adequadas. Do contrário, estar-se-á na ausência de qualquer critério econômico válido. A competitividade torna-se então assunto para as instituições voltadas para o longo prazo.

Coutinho e Ferraz (1994) realizaram uma ampla pesquisa sobre os determinantes e as condições competitivas na indústria brasileira. O objetivo foi subsidiar a formulação de estratégias de desenvolvimento competitivo e propor instrumentos e linhas de ação necessárias à sua implementação, bem como, induzir o debate e aumentar o grau de conscientização da sociedade brasileira, ao inserir a busca permanente da competitividade (no funcionamento da economia). O estudo destaca a noção de competitividade sistêmica como modo de expressar que o desempenho empresarial depende, e é também resultado, de fatores situados fora do âmbito de todas as empresas e da estrutura industrial da qual fazem parte, como a ordenação macroeconômica, as infraestruturas, o sistema político-institucional e as características socioeconômicas dos mercados nacionais.

Coutinho e Ferraz (1994) destacam também que, todos estes fatores são específicos a cada contexto nacional e devem ser explicitamente consideradas nas ações públicas ou privadas de indução de competitividade. Se observados dinamicamente, tanto o desempenho quanto a eficiência, são resultados de capacitações acumuladas e estratégias competitivas adotadas pelas empresas, em função de suas percepções quanto ao processo concorrencial e ao meio ambiente econômico onde estão inseridas

Nessa visão dinâmica, Teece, Pisano e Shuen (2002) afirmam que a competitividade deve ser entendida como a capacidade de a empresa formular e implementar estratégias concorrenciais que lhe permitam conservar, de forma duradoura, uma posição sustentável no mercado. Logo, o sucesso competitivo passa, assim, a depender da criação e renovação das vantagens competitivas por parte das empresas, em um processo em que cada produtor se esforça para obter peculiaridades que o distingam favoravelmente dos demais, como, por exemplo, custo e/ou preço mais baixo, melhor qualidade, menor lead-time, maior habilidade de servir à clientela, etc.

O sucesso implica também, que as empresas mostrem-se aptas não apenas a adotar estratégias competitivas adequadas, mas impor correções de rumo quando necessário. Para isto, as especificidades do mercado e do ambiente econômico e as modificações esperadas nas formas de concorrência são alguns dos elementos que devem nortear as firmas na seleção de suas estratégias. $\mathrm{O}$ conhecimento destas especificidades ajuda a inferir quais vantagens competitivas irão se traduzir em maiores vendas e rentabilidade (Coutinho e Ferraz, 1994). 
Qualquer que seja sua fonte, as vantagens competitivas, usualmente, requerem tempo para serem alcançadas. Essa característica é particularmente aplicável às vantagens associadas à inovação. Portanto, a análise da competitividade deve levar em conta a cumulatividade das vantagens competitivas adquiridas pelas empresas

Também é necessário que a empresa detenha capacidade para implementar a estratégia, sendo esta fundamentada não somente na capacitação técnica, mas também, no desempenho passado da firma. Desta forma, se traduz em capacidade financeira, relações com fornecedores e usuários, imagem conquistada, diferenciação de seus produtos, grau de concentração do mercado entre outros.

As organizações melhor sucedidas no mercado global têm sido firmas que conseguem demonstrar respostas precisas, rápidas, flexíveis, inovação de produtos, unida com capacidades gerenciais para efetivamente coordenar e redefinir as competências internas e externas.

Essas fontes de vantagens competitivas são as 'capacidades dinâmicas' (Teece, Pisano e Shuen, 2002). O termo dinâmico se refere ao caráter mutável do ambiente; há certas estratégias de resposta em mercados cujos tempos de resposta são críticos, o movimento da inovação é acelerado, e a natureza da competição futura e do mercado são difíceis de determinar. O termo capacidades enfatiza a posição do gerenciamento estratégico para uma adaptação apropriada, integrando e re-configurando as habilidades internas e externas, recursos, e competências funcionais por meio do ambiente em modificação.

Um passo fundamental na construção de um arcabouço conceitual relacionado com as capacidades dinâmicas é identificar os fundamentos, sobre os quais, vantagens distintivas e difíceis de serem replicadas, podem ser construídas. Teece, Pisano e Shuen (2002) ressaltam que, para ser estratégica, uma capacidade precisa estar alinhada com a necessidade do usuário. Isto é, ser única ou difícil de replicar. Assim, qualquer ativo ou entidade que seja homogênea e possa ser comprada e vendida no mercado a um preço estabelecido, não pode de nenhuma maneira, ser estratégica.

A proposta empírica deste artigo é, portanto, identificar estratégias empresariais de localização, inserção no mercado internacional e sua importância na explicação da variância da competitividade entre micro e pequenas empresas no estado de Minas Gerais.

\section{Estratégia empírica}

O presente trabalho mantém uma sequência de análise em consonância com os estudos realizados por Azzoni e Ferreira (1997) sobre as principais regiões (Sul e Nordeste) e os estados do Rio de Janeiro, São Paulo e Minas Gerais, dos seus níveis de competitividade. Os autores destacam que, os indicadores de competitividade revelam uma retomada, na década de 1990, da competitividade do setor industrial tradicional. Enquanto São Paulo apresenta uma reversão em sua tendência declinante, observada na década de 70 e na 
primeira metade da década de 80, Minas Gerais destaca-se com os melhores níveis de competitividade, principalmente, no setor de bens intermediários em relação às demais regiões analisadas. Ao julgar por essa competitividade, tanto em seus níveis como nas suas tendências, Azzoni e Ferreira (1997) afirmam que a área industrial tradicional do país requalifica-se, com grande potencial, para receber novos investimentos industriais, tanto no que se refere a novas plantas quanto ao próprio aumento da produção nas plantas existentes. Desta forma o presente artigo trata de uma amostra de micro e pequenas empresas do estado de Minas Gerais.

Para obter as informações relacionadas à competitividade das micro e pequenas empresas construiu-se um instrumento de coleta que contemplasse, primeiramente, as questões de classificação, caracterização da empresa e verificação de enquadramento. Em seguida foram incluídas questões que permitissem elencar os elementos disponíveis ao respondente no que tange à gestão, disponibilidade de ativos no município, qualidade da educação, fatores relacionados ao comércio exterior, cooperação, entre outros.

\subsection{Plano amostral e pesos amostrais}

Para elaborar o plano amostral inicial, os estabelecimentos de micro e pequeno porte da indústria de transformação de Minas Gerais foram divididos por setor de atividade. Foram considerados os estabelecimentos com pelo menos 1 e não mais que 99 funcionários. Desta forma, com base no cadastro da RAIS (Relação Anual de Informações Sociais) foram selecionados 28.804 estabelecimentos considerados de micro e 4.583 de pequeno porte, totalizando 33.387 empresas. Estes foram divididos em 21 setores, de acordo com a Classificação Nacional de Atividades Econômicas (CNAE).

Com base nessa primeira segmentação pode se constatar uma concentração da atividade industrial nos seguintes segmentos: confecção de artigos do vestuário e acessórios; fabricação de produtos alimentícios; fabricação de produtos de metal, exceto máquinas e equipamentos; fabricação de produtos de minerais não-metálicos; fabricação de móveis; preparação de couros e fabricação de artefatos de couro, artigos para viagem e calçados. Esses segmentos, individualmente, possuem mais do que $5 \%$ dos estabelecimentos do Estado e concentram, ao todo, 65\% de todas as empresas. Para a amostragem realizada no estudo, o plano inicial foi de amostrar esses setores para representar $30 \%$ da amostra.

Em seguida, os setores industriais que, individualmente, representam menos de $5 \%$ e mais de $1 \%$, totalizando cerca de $25 \%$ da amostra, foram ajustados de maneira complementar e representam 30\% da amostra. Esses setores são: impressão e reprodução de gravações; fabricação de produtos de madeira; fabricação de produtos diversos; fabricação de produtos têxteis; manutenção, reparação e instalação de máquinas e equipamentos; fabricação de produtos de borracha e de material plástico; fabricação de bebidas; fabricação de produtos do fumo. 
Por fim, os demais segmentos que representavam em seu conjunto $10 \% \mathrm{da}$ amostra foram amostrados para representar 40\%. O objetivo foi tentar captar os poucos estabelecimentos que se enquadram nesses segmentos de maior conteúdo tecnológico e valor agregado e incluir no estudo também as suas características. São os seguintes: fabricação de máquinas e equipamentos; fabricação de produtos químicos; metalurgia; fabricação de veículos automotores, reboques e carrocerias; fabricação de máquinas, aparelhos e materiais elétricos; fabricação de celulose, papel e produtos de papel; fabricação de equipamentos de informática, produtos eletrônicos e ópticos; fabricação de produtos farmoquímicos e farmacêuticos; fabricação de outros equipamentos de transporte, exceto veículos automotores; fabricação de coque, de produtos derivados do petróleo e de biocombustíveis.

Os estabelecimentos também foram localizados nas macroregiões do Estado para verificarmos como a indústria estava concentrada geograficamente, e as cotas em cada região, foram calculadas proporcionalmente à participação de cada região no número total de estabelecimentos.

\subsection{Problemas de viés de seleção}

Entre 29 de Janeiro de 2009 e 05 de Fevereiro de 2010 foram contatadas mais de 6.000 empresas para efetivar 800 entrevistas da pesquisa de Competitividade (média de 1:7). Esse tipo de esforço de pesquisa nunca é realizado sem algum tipo de acomodação em relação às condições objetivas da investigação de campo.

O primeiro problema encontrado na realização da pesquisa de campo foi em relação aos contatos disponíveis no cadastro da RAIS. Verificou-se que esses estavam desatualizados e em diversos casos, ao se tratarem de empresa de micro e pequeno porte, os contatos se referiam ao número do contador da empresa, que por questões éticas, não pode repassar o contato da empresa. Para mitigar esse problema na abordagem às empresas foi feito um trabalho de atualização e complementação desses dados para poder entrar em contato com os proprietários e diretores das empresas. Essa metodologia de abordagem consistia em realizar os sorteios pelo cadastro da RAIS e tentar o contato com a empresa, inicialmente, pelo contato apresentado nela, caso não fosse possível, estabelecer o contato pelos motivos expostos acima. $\mathrm{O}$ entrevistador tentava os dados de cadastro contidos nos cadastros acessórios, telefone disponível na internet, etc. Essa forma de abordagem pode introduzir viés em alguma medida na amostra observada, pois, não são todas as empresas da população que apresentam a mesma probabilidade de serem contatadas. Devido a essas limitações, decidiu-se aplicar uma análise numérica às informações coletadas e, além disso, não serão realizadas inferências. 


\subsection{Análise fatorial e variáveis latentes}

A análise fatorial é uma das técnicas mais usuais do que se convencionou chamar de análise multivariada. Quando empregamos este tipo de análise estamos frequentemente interessados no comportamento de uma variável ou grupos de variáveis em covariação com as demais.

As técnicas de análise multivariada são úteis para descobrir regularidades no comportamento de duas ou mais variáveis e para testar modelos alternativos de associação entre tais variáveis, incluindo a determinação de quando e como dois ou mais grupos diferem em seu perfil multivariado. Quando se analisam dados associados, espera-se explicar variações de acordo com um ou mais dos seguintes pontos de vista:

- Determinação da natureza e do grau de associação entre um conjunto de variáveis dependentes e um conjunto de variáveis independentes.

- Achar uma função ou fórmula pela qual nós podemos estimar valores das variáveis dependentes a partir das variáveis independentes, o chamado problema da regressão.

- Estabelecer a significância estatística associada aos itens anteriores.

A análise fatorial, em sua versão clássica de determinar os fatores ortogonais que descrevem aproximadamente e sucessivamente os vetoresresposta de $n$ indivíduos de um conjunto constituído por $m$ testes psicológicos. Este último trata, pela primeira vez, do que hoje se conhece como variáveis latentes.

$\mathrm{Na}$ realidade, a análise fatorial não se refere a uma única técnica estatística, mas a uma variedade de técnicas relacionadas para tornar os dados observados mais facilmente (e diretamente) interpretados. Isto é feito, analisando-se os inter-relacionamentos entre as variáveis, de tal modo que, estas possam ser descritas convenientemente por um grupo de categorias básicas, em número menor que as variáveis originais, chamados fatores. Assim, o objetivo da análise fatorial é a parcimônia, procurando definir o relacionamento entre as variáveis de modo simples, e usando um número de fatores menor que o número original de variáveis.

Mais precisamente, um fator é um construto, isto é, uma variável não observada, que se supõe estar subjacente a testes, escalas, itens e, de fato, medidas de qualquer espécie. As cargas fatoriais obtidas são, com efeito, reduções de dados muito mais complexos a tamanho manuseável para que o pesquisador possa interpretar melhor os resultados.

Em síntese, a análise fatorial é essencialmente um método para determinar o número de fatores existentes em um conjunto de dados, para determinar quais testes ou variáveis pertencem a quais fatores, e em que extensão os testes ou variáveis pertençam a/ou estão saturados com o que quer que seja o fator. 
Desta forma, a competitividade será analisada a partir das questões obtidas por meio do instrumento de coleta e "simplificadas" pela analise fatorial para obter os principais fatores relacionados à competitividade das Micro e Pequenas Empresas no estado de Minas Gerais.

\section{Resultados}

A análise fatorial foi empregada em $46^{1}$ variáveis originais entre provenientes dos questionários e de bases secundárias. O primeiro critério de validação da análise fatorial derivou dos testes KMO (Kaiser-Meyer-Olkin) e de esfericidade de Bartlet, uma vez que ambos os testes indicam a adequação dos dados a aplicação do método. O teste KMO é uma estatística que indica a proporção da variância dos dados originais que pode ser considerada comum a todas as variáveis. $\mathrm{O}$ teste varia entre 0 e 1 , sendo que quanto mais próximo de 1, maior é a adequação da amostra a análise fatorial. O teste de esfericidade de Bartlet testa se a matriz de correlação é uma matriz identidade, logo indicando que não haveria correlação entre os dados.

Tabela 1 - Testes KMO e Bartlett

\begin{tabular}{lc}
\hline Critérios & Valores \\
\hline Medida de adequação de Kaiser-Meyer-Olkin & 0,769 \\
Chi-quadrado aprox. & 1110472,66 \\
Teste de esfericidade de Bartlett & 861 \\
G.L. & 0,000 \\
Sig.
\end{tabular}

Fonte: Método de extração: Análise de componentes principais.

De acordo com a tabela 1 , ao analisar os resultados por intermédio dos critérios de Kaiser-Meyer-Olkin (KMO) cujo valor de 0,765 é considerado elevado e o de esfericidade de Bartlett com um nível de significância (1\%), rejeita-se a hipótese nula de que os dados não são adequados para a aplicação da análise fatorial.

O critério de Kaiser (retenção dos autovalores superiores a 1) foi empregado para a escolha do número de componentes. Assim, de acordo com a tabela 2 abaixo, primeiramente, selecionou-se 14 componentes que explicam $81,85 \%$ da variância total, sendo que a primeira componente é responsável por $10,60 \%{ }^{2}$.

\footnotetext{
1 Embora originalmente empregou-se 73 variáveis no trabalho, parte dessas variáveis foram excluídas, uma vez que apresentaram valores de comunalidade inferiores a 0,5 . Os valores de comunalidade variam entre 0 e 1 e quanto mais próximo de 1, maior o grau de explicação das variáveis inseridas no modelo pelos fatores comuns. Os valores da comunalidade são mostrados na tabela A.1 no anexo

2 Os fatores apresentados na tabela A.2 (anexo) são de difícil interpretação devido à similaridade numérica presente entre elas. Nesse caso, haveria a possibilidade da ocorrência de uma violação da suposição de ortogonalidade e, ademais, a organização em grupos de variáveis originais torna-se de difícil interpretação. Nesse caso, é importante realizar uma transformação ortogonal sobre os fatores originais com o objetivo de se encontrar uma estrutura para os pesos de forma que cada variável tenha peso alto em um único fator e pesos baixos e/ou moderados nos demais. Dessa forma, empregou-se o critério Varimax devido à simplicidade e por ser largamente empregado na literatura. O método minimiza o número de variáveis com loadings elevados em um fator, e, portanto, elimina os loadings com valores intermediários. Em outras palavras, cada variável original estará fortemente correlacionada com apenas uma única componente.
} 
Flávio de Oliveira Gonçalves, Marco Túlio Aniceto França, Rodrigo Gomes Marques Silvestre

Tabela 2 - Variância total explicada

\begin{tabular}{l|rrr|rrr}
\hline \multirow{2}{*}{ Componentes } & \multicolumn{3}{|c|}{ Autovalores iniciais } & \multicolumn{3}{c}{ Extração da soma dos quadrados } \\
& \multicolumn{3}{|c}{ rotacionada } \\
\cline { 2 - 7 } & Total & $\begin{array}{c}\text { \% de } \\
\text { Variância }\end{array}$ & $\begin{array}{c}\text { Acumulado } \\
\text { Acura de }\end{array}$ & Total & $\begin{array}{c}\text { \% } \\
\text { Variância }\end{array}$ & Acumulado \\
\hline 1 & 5,393 & 12,839 & 12,839 & 4,454 & 10,604 & 10,604 \\
2 & 4,677 & 11,135 & 23,975 & 4,315 & 10,273 & 20,877 \\
3 & 4,167 & 9,923 & 33,897 & 3,038 & 7,233 & 28,11 \\
4 & 3,259 & 7,759 & 41,656 & 3,032 & 7,218 & 35,328 \\
5 & 2,676 & 6,372 & 48,028 & 2,903 & 6,911 & 42,239 \\
6 & 2,44 & 5,81 & 53,838 & 2,613 & 6,222 & 48,461 \\
7 & 2,102 & 5,005 & 58,843 & 2,529 & 6,02 & 54,481 \\
8 & 1,83 & 4,356 & 63,199 & 2,285 & 5,44 & 59,922 \\
9 & 1,704 & 4,058 & 67,256 & 1,935 & 4,607 & 64,529 \\
10 & 1,453 & 3,46 & 70,716 & 1,912 & 4,552 & 69,081 \\
11 & 1,373 & 3,268 & 73,984 & 1,54 & 3,666 & 72,748 \\
12 & 1,215 & 2,894 & 76,878 & 1,337 & 3,185 & 75,932 \\
13 & 1,087 & 2,589 & 79,467 & 1,309 & 3,116 & 79,048 \\
14 & 1,001 & 2,384 & 81,851 & 1,177 & 2,803 & 81,851 \\
\hline
\end{tabular}

Fonte: Método de extração - análise de componentes principais.

Embora tenham surgido 14 componentes oriundos da análise fatorial, o passo seguinte, será a adoção do critério de alpha de cronbach para testar a consistência interna das variáveis dentro de cada um dos fatores como critério de descarte. O critério empregado foi o de valores inferiores a 0,6. Dessa forma, ficaremos com 11 fatores, ao invés, dos 14 iniciais.

Tabela 3 - Consistência Interna dos fatores

\begin{tabular}{lcccc}
\hline Componentes & Alpha de Cronbach & Componentes & Alpha de Cronbach \\
\hline 1 & 0,956 & 8 & 0,763 \\
2 & 0,642 & 9 & 0,711 \\
3 & 0,948 & 10 & 0,941 \\
4 & 0,833 & 11 & 0,668 \\
5 & 0,96 & 12 & 0,458 \\
6 & 0,866 & 13 & 0,419 \\
7 & 0,9 & 14 & 0,275 \\
\hline
\end{tabular}

Fonte: Elaboração própria.

A tabela A.3 (anexo) mostra as 11 componentes, após serem rotacionadas, de acordo com a carga fatorial (em ordem decrescente) das variáveis mais relevantes. Após a rotação, as componentes se tornaram de fácil interpretação podendo denotá-las de acordo com o percentual da variância explicada dos dados originais. Além disso, as componentes foram normalizadas apresentando valores entre 0 e 1 e os gráficos de kernel mostrados na sequência revela a 
distribuição de cada uma das componentes.

A Componente 1 é aquela que explica a maior variância total $(10,60 \%)$ e possui características relacionadas à exportação. É composta por questões relacionadas à freqüência com que a firma exporta e se os produtos, na opinião do empresário, possuem vantagens competitivas frente aos demais concorrentes no mercado nacional e internacional.

Ao explicitar a relevância da inserção das firmas no comércio externo como indicador da competitividade pode-se retomar o argumento de Krugman (1996) de que, em nível macro, em muitas correntes de investigação, a competitividade se confunde com o debate de comércio exterior. Isso pode ocorrer pela grande relevância desse fator, seja como resultado de estratégias competitivas quanto como fonte de aprendizado e submissão a um ambiente de seleção mais competitivo.

Especificamente sobre as empresas observadas, pode-se notar no gráfico 1 (abaixo), a existência de multimodalidade em sua distribuição, isto é, um grande grupo cujos estabelecimentos pouco exportam e diversos pequenos grupos ao longo da distribuição com níveis maiores de exportação. Desta forma, sendo a inserção no comércio externo um fator intensamente correlacionado com a miríade de variáveis investigadas, e dado o baixo grau de inserção (aparente) das Micro e Pequenas Empresas nesse mesmo comércio. Uma oportunidade seria focar as ações a fim de melhorar a competitividade na inserção comercial das MPE, não só pela relevância, mas também pela grande margem de melhoria.

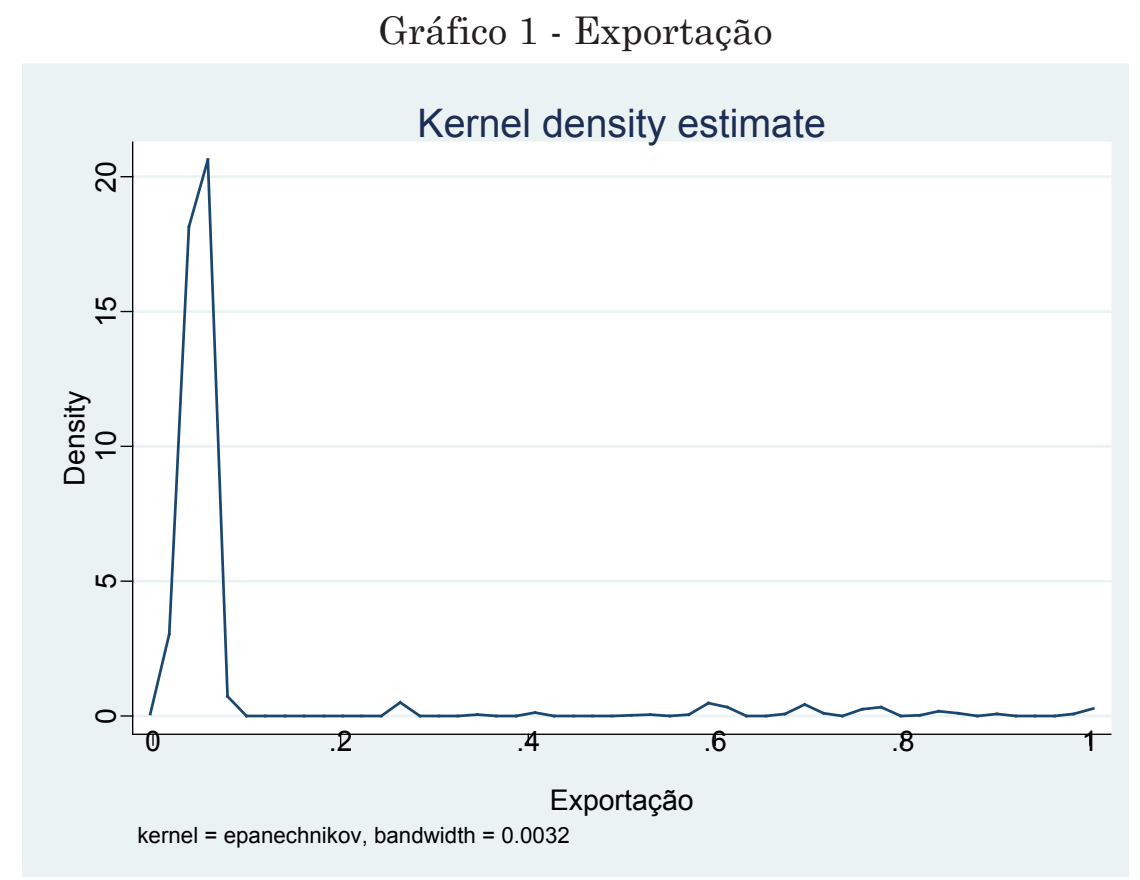

Fonte: elaboração própria. 
A Componente 2 possui a segunda maior variância explicada $(10,27 \%)$ e é composta por variáveis estruturais como os investimentos realizados pelos municípios, o número de universidades e de centros de pesquisa, a quantidade de estabelecimentos industriais e a razão entre trabalhadores com ensino superior em relação a quantidade de indústrias. Esse fator guarda relação com a dimensão estrutural proposta por Coutinho e Ferraz (1994), ou seja, os investimentos em ativos como os descritos acima são relevantes para a competitividade. A existência desses ativos é, inclusive, um determinante que contribui para a concentração da atividade industrial, como se apresenta nas regiões em torno das capitais.

O gráfico 2 (abaixo), mostra a existência de uma distribuição bimodal marcada por dois grandes grupos cujos estabelecimentos, em sua maioria, estão em cidades com baixa ou média infraestrutura.Os estabelecimentos constantes na moda de alta infraestrutura estão localizados na capital do estado. Parece ser uma evidência de que a necessidade de proximidade com os atores locais, como destacado por Maskel e Malmberg (1999), são importantes na determinação dos padrões competitivos da empresa.

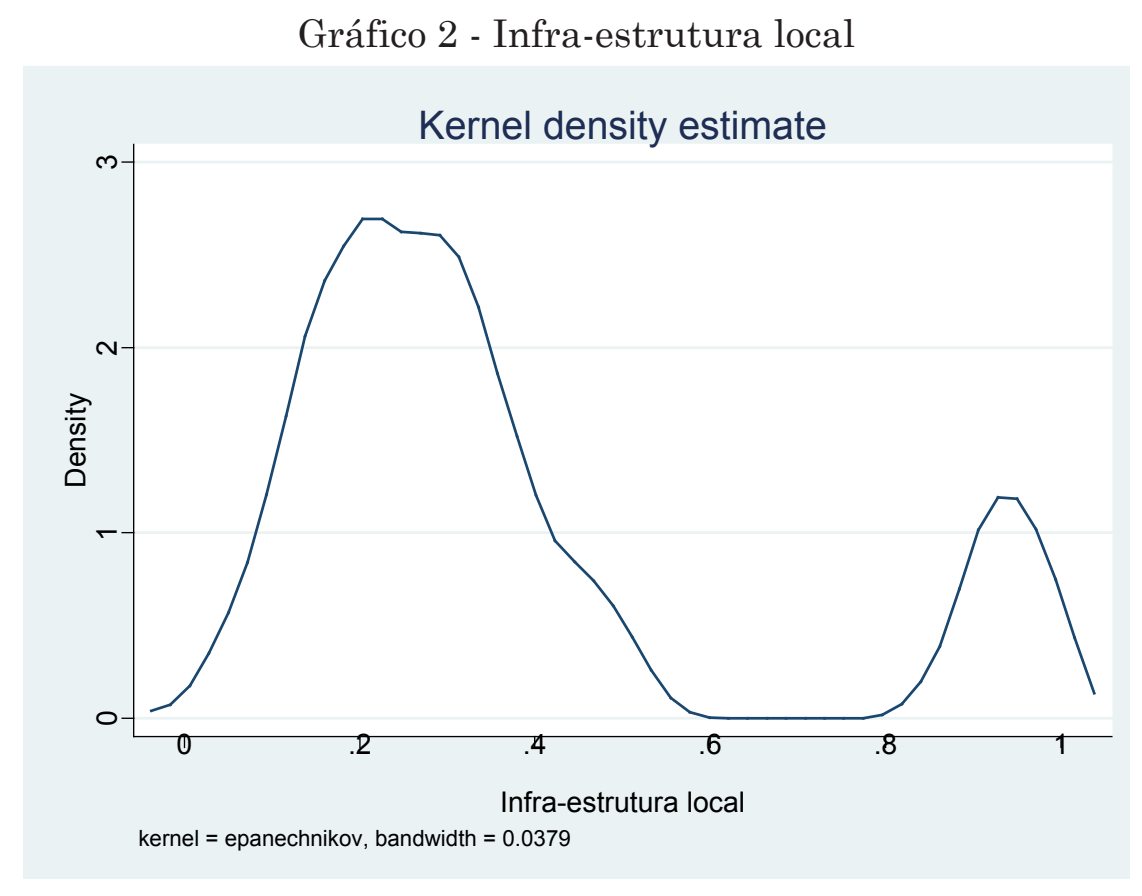

Fonte: elaboração própria.

A Componente 3 (7,23\% de explicação da variância total) também possui características sistêmicas e é relativa às questões referentes às importações de máquinas e equipamentos e com qual frequência a atividade é realizada. Essencialmente, esse fator está relacionado com o fluxo internacional de tecnologia, ou seja, a aquisição de máquinas e equipamentos cria oportunidades de elevação de produtividade e entrada de novos conhecimentos na firma e no setor. De certa maneira também, esse fator se relaciona com aspectos do comércio exterior, mas afetando outras variáveis da competividade. 
O gráfico 3 (abaixo) apresenta distribuição multimodal com baixa frequência nas modas de maior competitividade. Existe um grande grupo cuja atividade de importação de máquinas é baixa. Esta distribuição mostra a oportunidade de ganhos de produtividade ao se adotar políticas de incentivo de importação de bens de capital e a tecnologia incorporada nestes.

Gráfico 3 - Impotação de máquinas e equipamentos

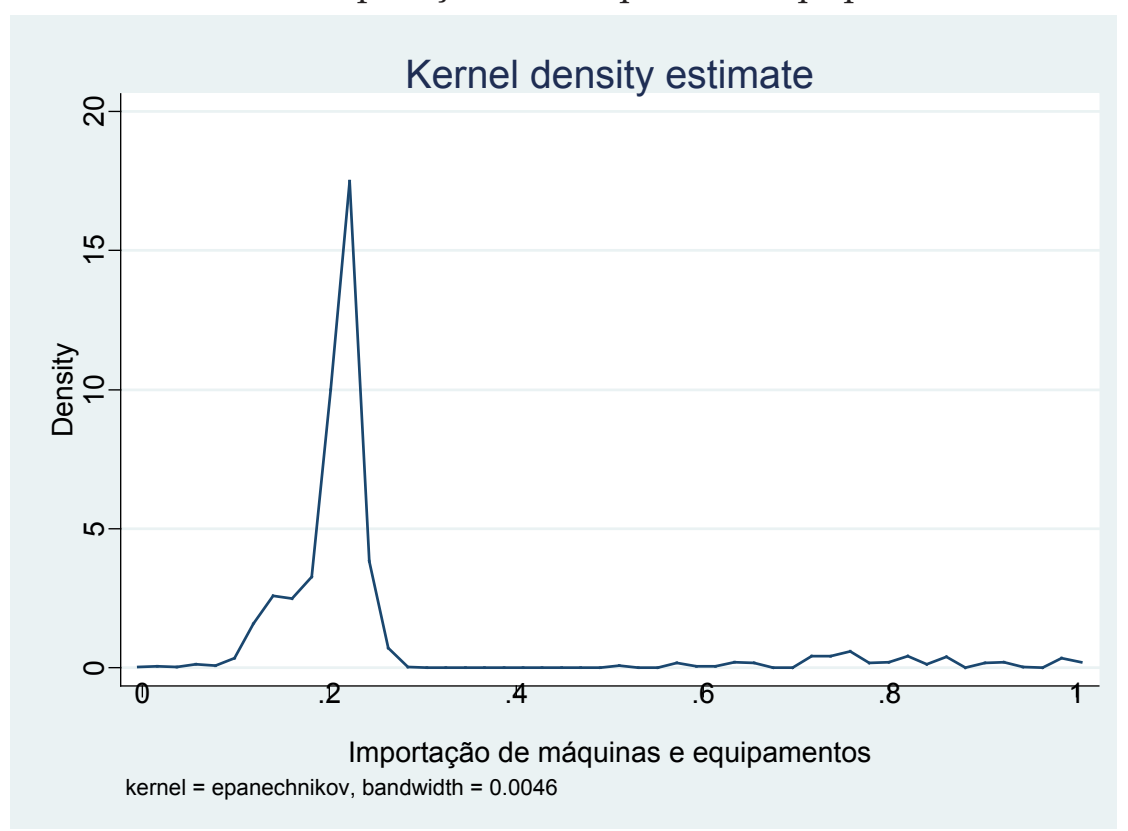

Fonte: elaboração própria.

A Componente 4 (7,22\% da variância total) é estrutural e corresponde a qualidade da mão-de-obra básica. As médias referentes ao Enem e a Prova Brasil para as séries finais do ensino fundamental foram reunidas em uma mesma componente. Enquanto o Enem mensura a qualidade do nível educacional de jovens concluintes do ensino médio, a Prova Brasil mede o conhecimento no momento da entrada nesse nível de ensino. Além disso, é a partir dessa faixa etária, que o indivíduo pode ingressar no mercado de trabalho como aprendiz. Em outras palavras, seria o papel do capital humano no estímulo ao aumento da produtividade via a incorporação e/ou o desenvolvimento de tecnologias mais complexas. Na opinião de Coutinho e Ferraz (1994), a qualidade da mão de obra seria um fator que está além da estrutura industrial e que tem impacto sobre a competitividade. O gráfico 4 (abaixo) mostra uma distribuição bimodal cuja moda seria 0,6 e 0,7, respectivamente. A distribuição desta dimensão se mostra menos desigual que as anteriores, provavelmente pelas políticas educacionais adotadas pelo estado nos últimos anos, favorecendo uma homogeneização da qualidade do capital humano disponível nos diversos municípios. 
Gráfico 4 - Capital Humano (Qualidade da mão-de-obra básica)

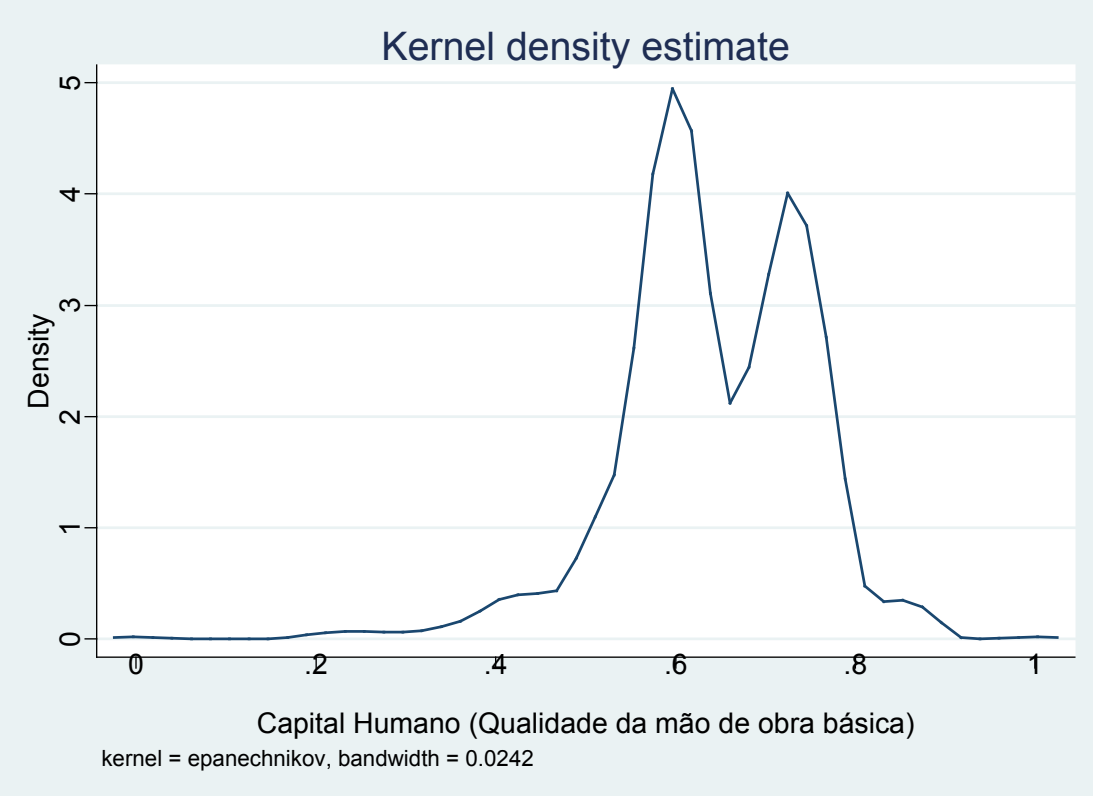

Fonte: elaboração própria.

A Componente 5 (6,91\% da variância total) possui aspectos sistêmicos e corresponde a importação de matérias-primas. As principais questões estão relacionadas à opinião do empresário e se realizou a atividade. É importante observar que, o gráfico 5 (abaixo) é semelhante ao gráfico 3, isto é, também mostra uma multimodalidade com baixa frequência nas modas superiores na distribuição cuja ênfase é a importação de máquinas e equipamentos. Em síntese, novamente pode-se destacar a participação no comérciointernacional, agora para importação de matérias-primas como outro fator a ser considerado na análise da competitividade.

Gráfico 5 - Importações de matérias primas

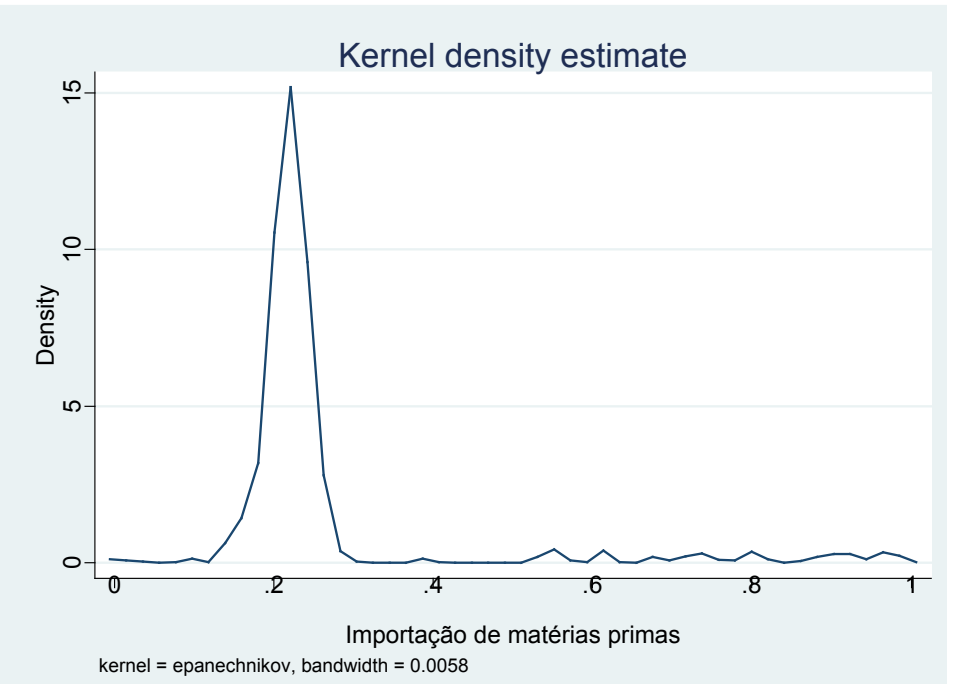

Fonte: elaboração própria. 
A Componente 6 (6,22\% da variância total) apresenta características estruturais e mensura a qualidade da mão-de-obra de nível superior, uma vez que capta tanto os ingressantes quanto os concluintes desse nível de ensino. Ademais, incorpora o indicador de investimento em capital fixo. Esta componente destaca a correlação entre a importação de bens de capital com tecnologia incorporada e a preparação da mão de obra para realizar o potencial de produtividade constante nestes. O gráfico 6 (abaixo) apresenta bimodalidade na distribuição com valores bastante distintos cuja moda apresenta valores de 0,25 e 0,7 , respectivamente. É importante destacar que, a primeira vista, a qualidade desse componente mostra-se elevada no estado, provavelmente, consequência do grande número de universidades públicas federais e privadas. Como havíamos observado para a componente que avalia a necessidade de mão de obra básica, a qualidade da mão de obra de nível superior assim como, o capital físico investido, depende de características locais que, muitas vezes, estão além da estrutura industrial.

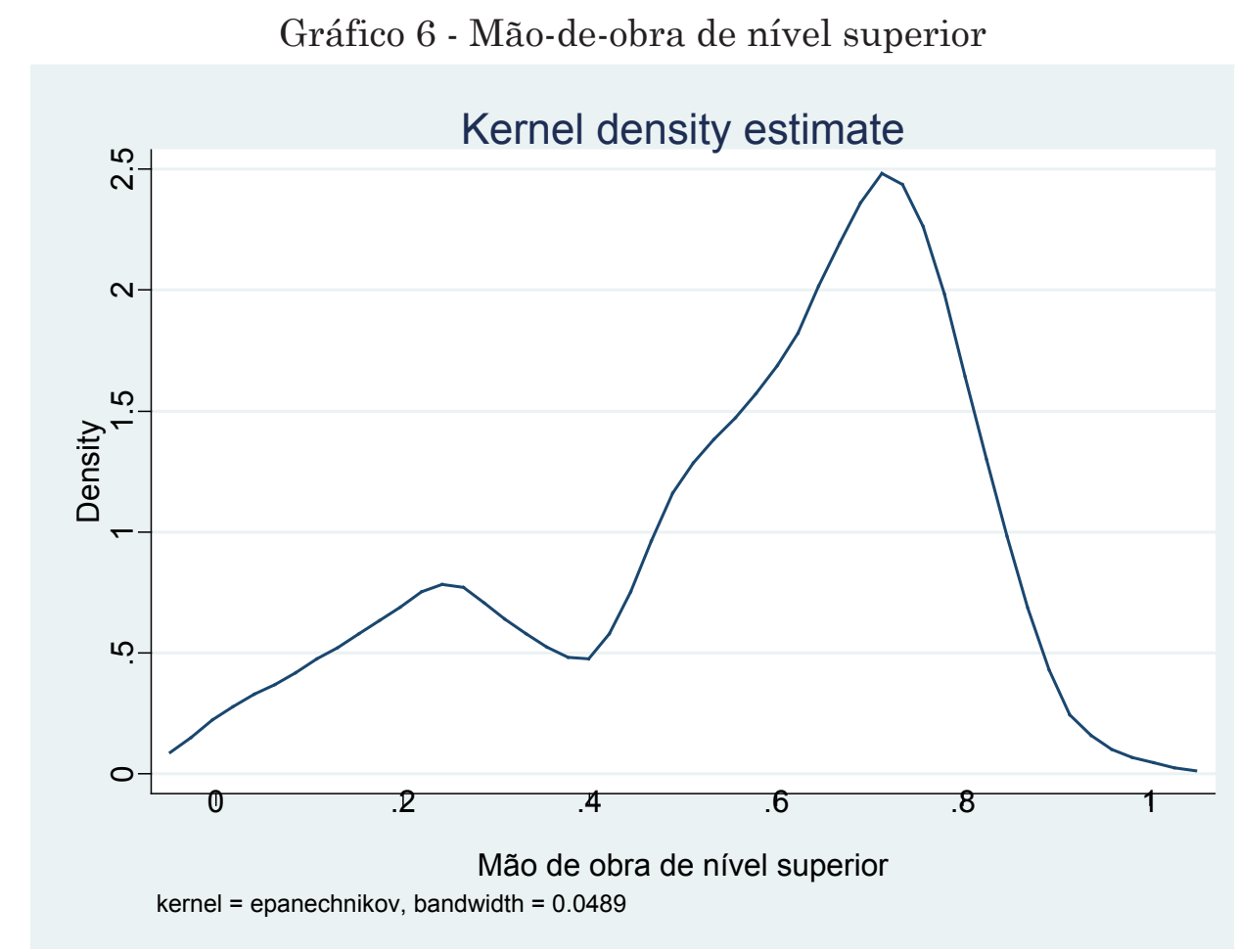

Fonte: elaboração própria.

A Componente 7 (6,02\% de explicação da variância total) corresponde ao aspecto empresarial e capta a elaboração das estratégias por parte da empresa. As variáveis que a compõem dizem respeito ao envolvimento dos funcionários na elaboração e perseguição das metas e se a empresa possui planos estruturados para alcançar os objetivos. De acordo com Kupfer (1992), o padrão de competitividade futuro é determinado pela adequação das estratégias adotadas no presente. Logo, a adoção dessas práticas é um dos determinantes para a competitividade futura. O gráfico 7 (abaixo) mostra claramente a existência de uma distribuição bimodal cujas modas apresentam valores bastante distintos. Ao observar o desvio padrão, as empresas que pertencem ao primeiro grupo 
seriam mais semelhantes entre si no que tange à essa componente em comparação àquelas que pertencem ao segundo grupo.

Gráfico 7 - Elaboração das estratégias e planos estruturados

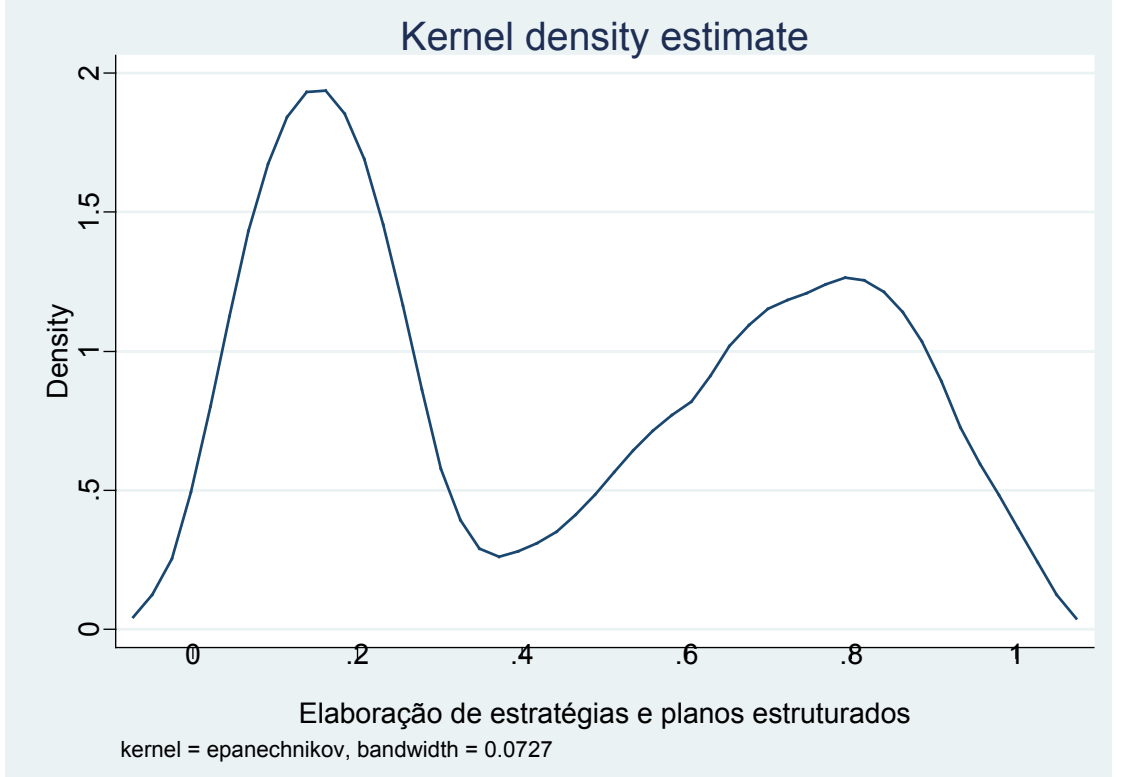

Fonte: elaboração própria.

A Componente 8 (4,36\% da variância total) é empresarial e corresponde a necessidade de mão-de-obra altamente especializada (engenheiros, mestres e doutores). A variável é formada por questões relativas à necessidade e ao percentual de trabalhadores com grau elevado de qualificação presentes na empresa. Embora não seja muito claro, a princípio, afirmaríamos a existência de multimodalidade (três grupos) cuja necessidade de mão-de-obra especializada não se mostra muito diferente entre eles, pois, as modas em cada um dos grupos corresponderiam aos valores de 0,1, 0,25 e 0,4, respectivamente. 
Dimensões latentes da competitividade da micro e pequena indústria de transformação ...

Gráfico 8 - Necessidade de mão-de-obra altamente especializada

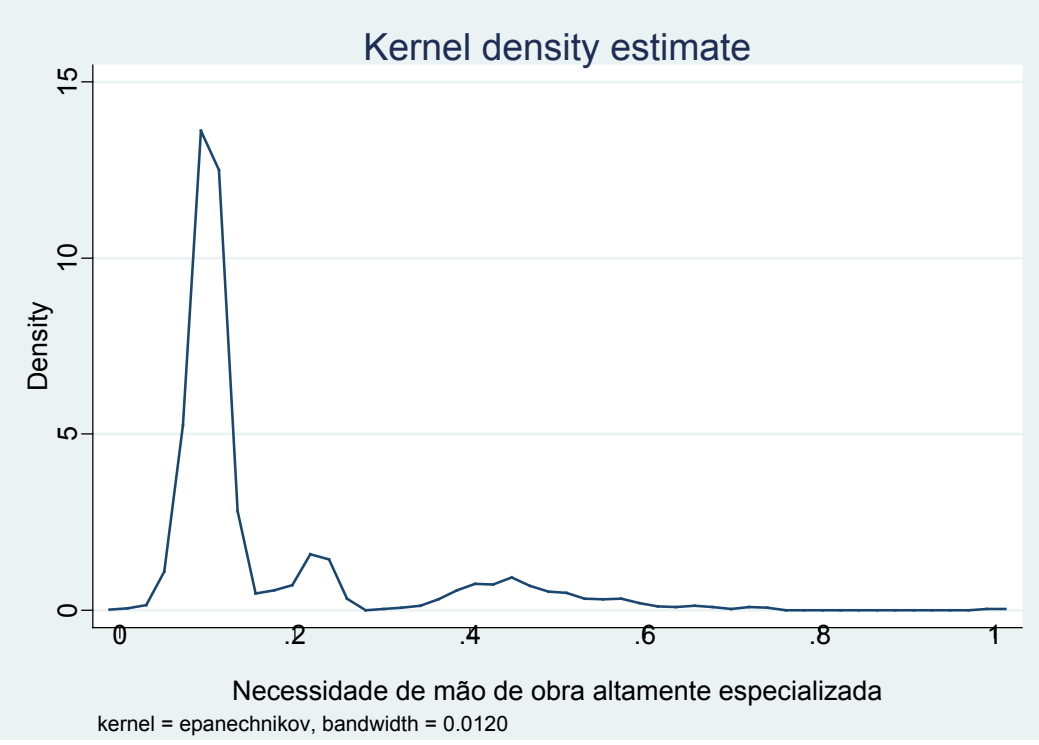

Fonte: elaboração própria.

A Componente $9(4,61 \%$ da variância total) é sistêmica e referese à pretensão de importar insumos. Diferente das componentes 3 e 5 cujas distribuições mostraram padrões semelhantes, essa distribuição apresenta três diferentes grupos, sendo o maior deles, formado por estabelecimentos que não pretendem importar. Isto é, grande parte dos estabelecimentos não faz planos para participar do fluxo internacional de comércio, o que como visto anteriormente poderia trazer maior competitividade às firmas.

Gráfico 9 - Pretenção para a realização de importação de insumos

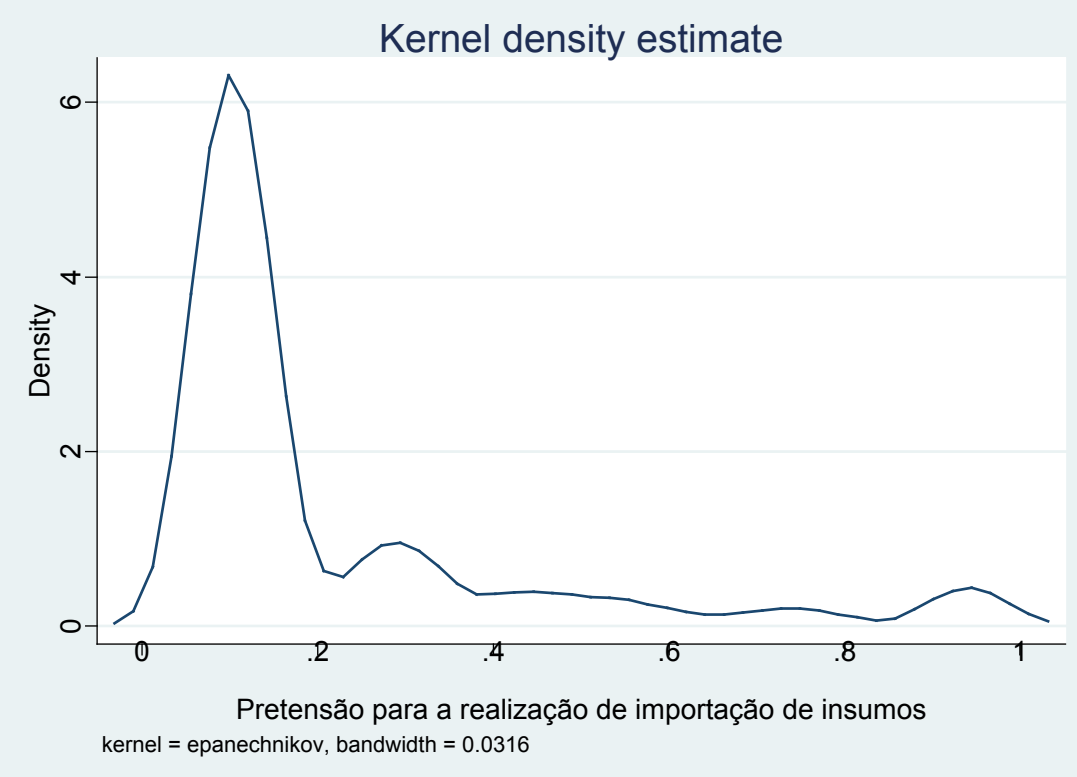

Fonte: elaboração própria. 
A Componente 10 (com 4,55\% de participação na variância total) é sistêmica e mostra semelhanças em relação ao caso anterior, pois, as questões relevantes dizem respeito a opinião empresarial em torno do ato de importar insumos e se a atividade foi realizada no último ano. A distribuição tem grande concentração em níveis baixos de importação e reconhecimento da importância de participação no comércio internacional.

Gráfico 10 - Opinião do empresário em torno da importância de se importar isumos

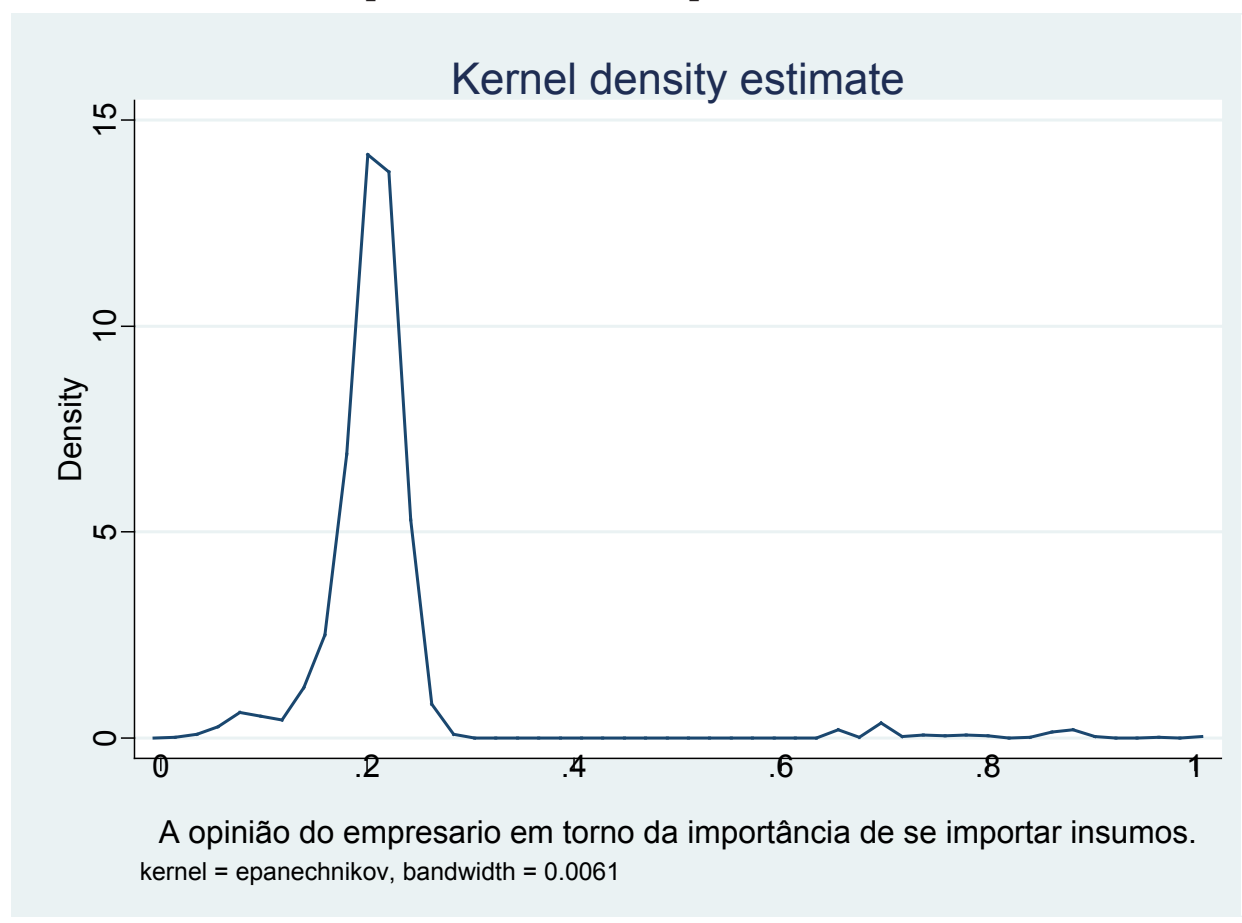

Fonte: elaboração própria.

A Componente 11 (com 3,67\% de explicação da variância) apresenta características empresariais e corresponde a atribuição bem definida de papéis e responsabilidades aos sócios e funcionários. Observa-se que existem três grupos de estabelecimentos que atribuem papéis e responsabilidades aos sócios. Embora seja uma função importante para a empresa, é a componente que possui menor relevância dentre às demais. 
Gráfico 11 - Atribuição de papéis e responsabilidades aos sócios

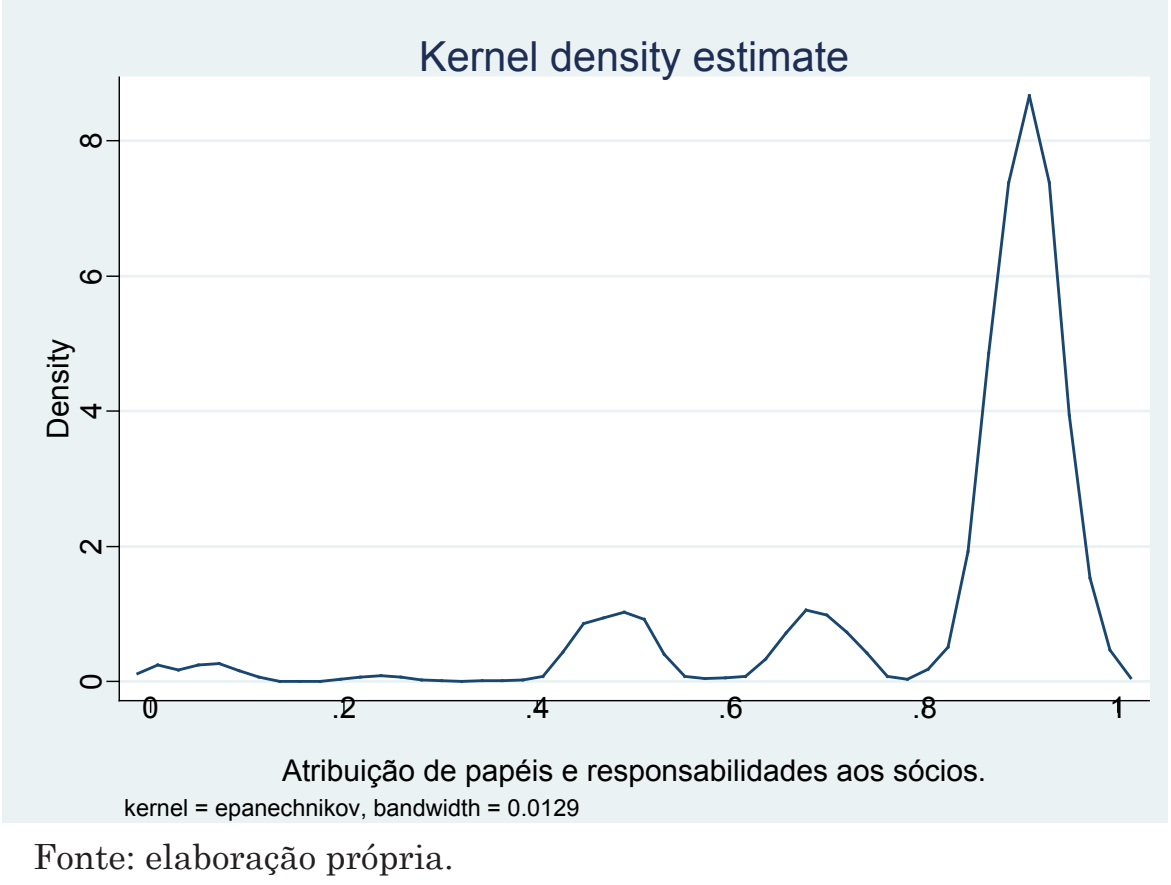

Dos onze fatores extraídos da análise numérica, o principal e mais dois outros, destacam a relevância da inserção das empresas no comércio internacional, desde a efetiva venda de produtos no mercado externo até a importação de máquinas, equipamentos e insumos. Esse é um aspecto relevante a ser considerado entre as variáveis latentes da competitividade. A participação no fluxo internacional de mercadorias expõe as firmas a um ambiente de maior concorrência e exigem estratégias mais competitivas. Estas estratégias passam pela utilização de bens de capital com tecnologia incorporada, bem como o aproveitamento de preços de insumos disponíveis internacionalmente.

Os fatores estruturais, como disponibilidade de centros de pesquisa, capacidade de investimento dos municípios, qualidade da mão-de-obra, também são preponderantes para compreender as diferenças no que concerne à competitividade. Entretanto, nesse aspecto, particularmente em relação à qualidade da mão-de-obra, pode-se observar que a grande disponibilidade de instituições de ensino em Minas Gerais tem impacto positivo sobre os resultados nas empresas observadas. Especialmente porque as entidades públicas federais, estaduais e privadas do Estado têm oferecido qualidade no ensino.

Conforme esperado, os fatores ligados ao gerenciamento da micro e pequena empresa tiveram pouco impacto na variância total das variáveis ligadas à competitividade. $\mathrm{O}$ desenvolvimento destas firmas depende mais de fatores sistêmicos que afetem os incentivos para participação no comércio internacional (câmbio, tarifas, custos logísticos e barreiras não tarifárias) e fatores regionais como disponibilidade de mão de obra de qualidade que propriamente de decisões estratégicas dos micro e pequenos empresários. Esta conclusão deve, porém, ser relativizada pela característica do objeto de estudo. Micro e pequenas empresas competitivas tendem no logo prazo a se tornarem médias e grandes, o que traz um viés de seleção em nossa análise. 


\section{Considerações finais}

O presente artigo tratou da investigação sobre as dimensões latentes da competitividade da micro e pequena empresa com base em uma analise numérica para o estado de Minas Gerais.

A principal conclusão está na relevância da inserção no mercado internacional para entender a competitividade, tanto nos aspectos relacionados à venda da produção como para a compra de insumos, máquinas e equipamentos. O foco na inserção internacional não só apresenta maior relevância nos resultados quanto demonstra maior margem para melhoria. Observando a distribuição dos fatores ligados ao comércio internacional pode-se observar uma grande distância entre as firmas, com um grande grupo que não participa desta atividade. Desta forma, oportunidades de políticas públicas que visem facilitar a inserção das firmas, sejam como exportadoras, seja como importadoras, podem trazer ganhos de competitividade às MPEs.

A valorização de fatores como infraestrutura local também são relevantes, contudo, tem menores oportunidades de melhoria. Na infraestrutura ainda existe uma grande disparidade entre a disponibilidade de ativos entre o município de Belo Horizonte e o restante do Estado. O que reflete a grande concentração da atividade econômica industrial na capital. A educação apresenta o resultado das politicas de melhoria na qualidade da educação (da básica à superior) e expansão da rede federal, estadual e privada no Estado.

Fatores relativos à capacidade dinâmica das firmas também foram identificados, estes, porém, tem um papel menor na determinação da competitividade da Micro e Pequena Empresa. Tal conclusão, porém, deve ser feita com cautela, pois as firmas mais competitivas ao se tornarem médias e grandes empresas estão fora do universo estudado.

O aumento da competitividade destas firmas de grande importância na oferta de emprego e como porta de entrada do empreendedorismo passa por uma maior integração ao comércio internacional, maior oferta de ativos institucionais de formação de mão-de-obra e infraestrutura.

\section{Referências}

Azzoni, Carlos R.; Ferreira, Dirceu A. (2012). Competitividade regional e reconcentração industrial: o futuro das desigualdades regionais no Brasil. Trabalho desenvolvido junto ao Núcleo de Estudos e Modelos Espaciais Sistêmicos (Nemesis). URL: <http://www.nemesis.org.br/artigos/a0004.pdf>. Acesso em: 20 fev. 2012.

Coutinho, Luciano \& Ferraz, José Carlos. (1994). Estudo da competitividade da indústria brasileira. 2 ed. Campinas: Papirus/ Ed. da Unicamp.

IBGE, (2003). "As micro e pequenas empresas comerciais e de serviços no Brasil 2001" Estudos e pesquisas informação econômica, n.1. Rio de Janeiro. 
Dimensões latentes da competitividade da micro e pequena indústria de transformação ...

Krugman, Paul R. (1996). "Making sense of the competitiveness debate". Oxford Review of Economic Policy, vol. 12(3).

Kupfer, David. (1992). "Padrões de concorrência e competitividade". Texto de Discussão, 265, UFRJ. URL: < http://www.ie.ufrj.br/gic/pdfs/1992-2_Kupfer.pdf>.

Maskell, Peter; Malmberg, Anders. (1999). "Localised learning and industrial competitiveness". Cambridge Journal of Economics, vol. 23; p. 167-185.

Teece, D.; Pisano, G.; Shuen, A. (2002). "Dynamic capabilities and strategic management". The nature and dynamics of organizational capabilities. Oxford. 


\begin{tabular}{|c|c|c|c|c|c|c|c|c|c|c|c|c|}
\hline \begin{tabular}{l}
$D$ \\
$D$ \\
0 \\
3 \\
0 \\
0 \\
0 \\
0 \\
0 \\
0 \\
0 \\
0 \\
0 \\
0 \\
\multirow{2}{*}{} \\
0
\end{tabular} & 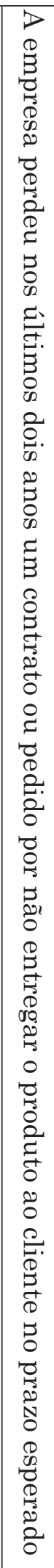 & 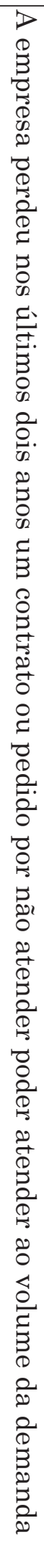 & 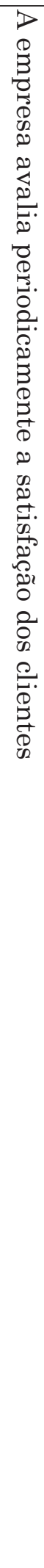 & 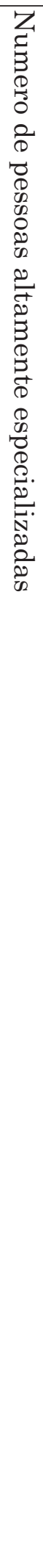 & 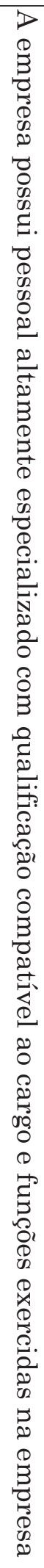 & 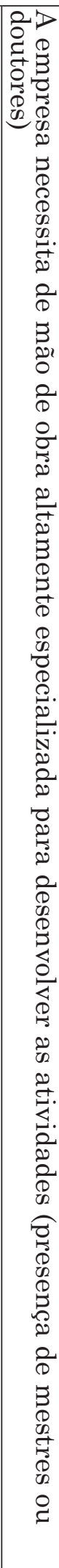 & 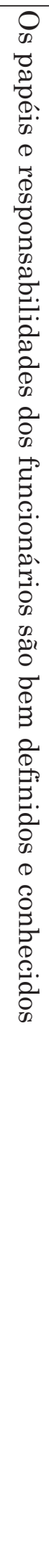 & 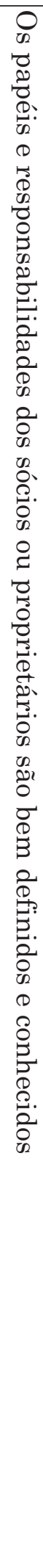 & 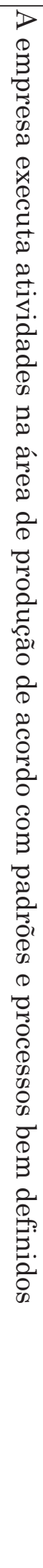 & 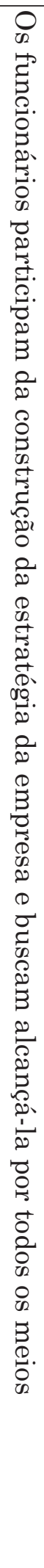 & 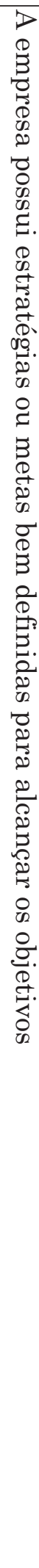 & 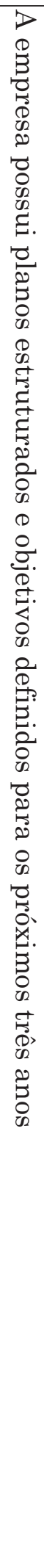 \\
\hline 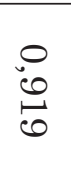 & $\begin{array}{l}0 \\
\stackrel{8}{0} \\
8\end{array}$ & 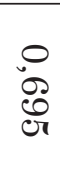 & $\begin{array}{l}0 \\
0 \\
\infty \\
\infty \\
0\end{array}$ & $\begin{array}{l}0 \\
\stackrel{0}{\sigma} \\
\sigma\end{array}$ & $\begin{array}{l}\circ \\
\infty \\
\infty \\
\stackrel{\infty}{\circ}\end{array}$ & $\begin{array}{l}0 \\
\text { 己̈ } \\
\text { or }\end{array}$ & $\begin{array}{l}0 \\
\stackrel{0}{\circ} \\
\text { న్ }\end{array}$ & 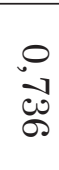 & OS & $\begin{array}{l}0 \\
\text { ปै } \\
\text { वै }\end{array}$ & $\begin{array}{l}0 \\
\infty \\
\infty \\
\infty\end{array}$ & $\begin{array}{l}0 \\
\infty \\
\mathbb{D} \\
\vec{\sigma}\end{array}$ \\
\hline
\end{tabular}




\begin{tabular}{|c|c|c|c|c|c|c|c|c|c|c|c|c|c|c|}
\hline 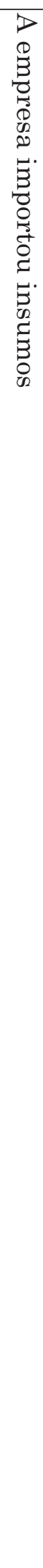 & 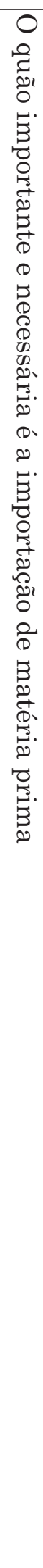 & 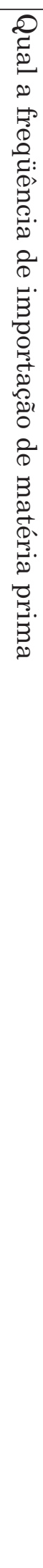 & 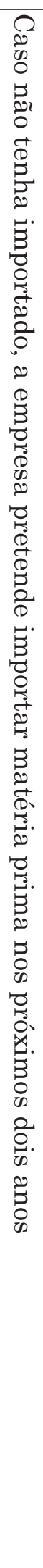 & 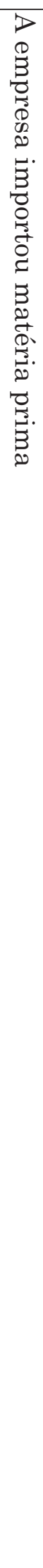 & 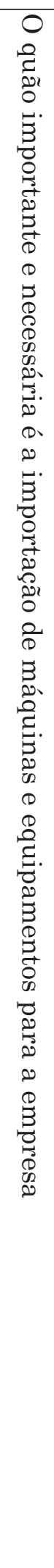 & 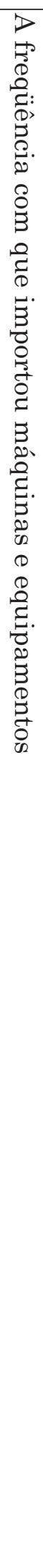 & 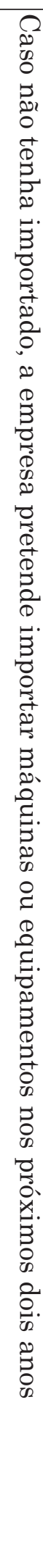 & 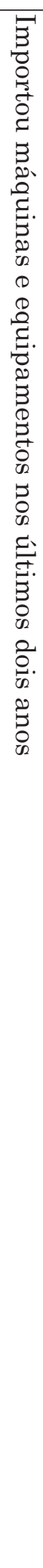 & 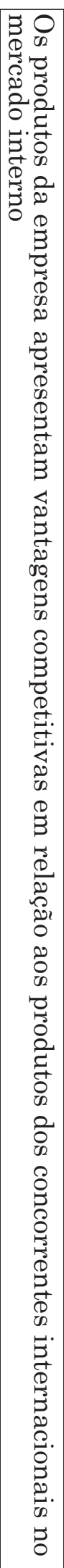 & 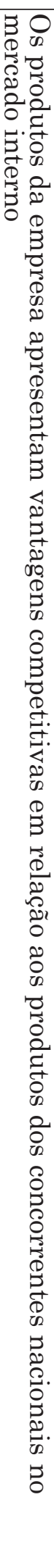 & 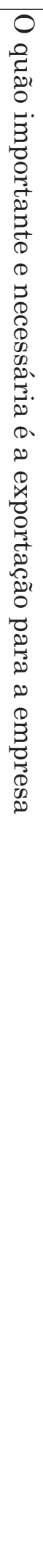 & 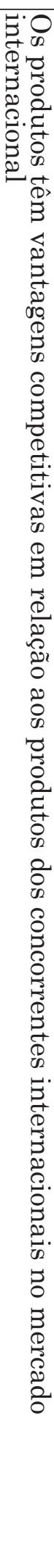 & 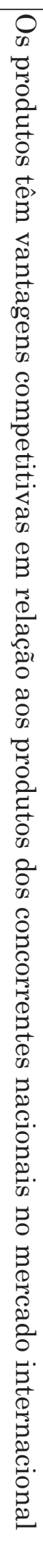 & 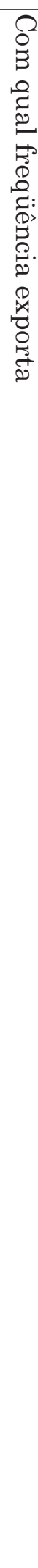 \\
\hline $\begin{array}{l}0 \\
0 \\
0 \\
\infty \\
\infty\end{array}$ & 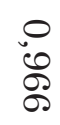 & $\begin{array}{l}0 \\
0 \\
0 \\
0 \\
0\end{array}$ & $\begin{array}{l}0 \\
07 \\
0 \\
-1\end{array}$ & $\begin{array}{l}0 \\
c \\
c\end{array}$ & $\begin{array}{l}0 \\
0 \\
\mathbb{N} \\
\delta\end{array}$ & $\begin{array}{l}0 \\
\infty \\
\infty \\
\infty \\
0\end{array}$ & ब & $\begin{array}{l}0 \\
0 \\
0 \\
0\end{array}$ & ֻे & $\begin{array}{l}\circ \\
\stackrel{0}{\circ} \\
\stackrel{8}{1}\end{array}$ & $\begin{array}{l}0 \\
\infty \\
\infty \\
\infty\end{array}$ & $\begin{array}{l}\circ \\
\infty \\
\infty\end{array}$ & $\begin{array}{l}0 \\
0 \\
\stackrel{0}{0} \\
0\end{array}$ & $\begin{array}{l}0 \\
\infty \\
\infty \\
\infty\end{array}$ \\
\hline
\end{tabular}




\begin{tabular}{|c|c|c|c|c|c|c|c|c|c|c|c|c|c|}
\hline 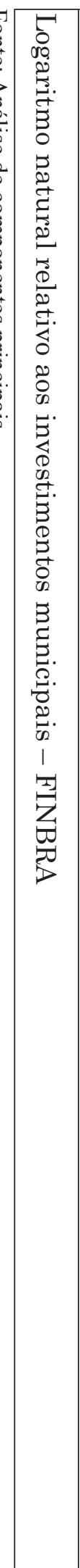 & 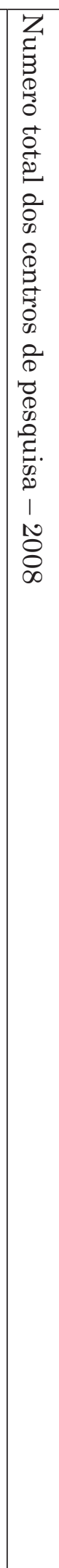 & 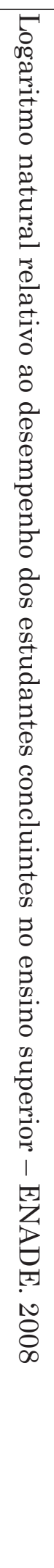 & 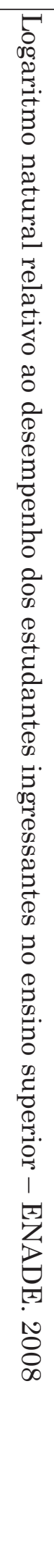 & 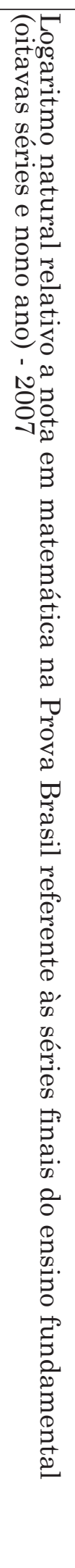 & 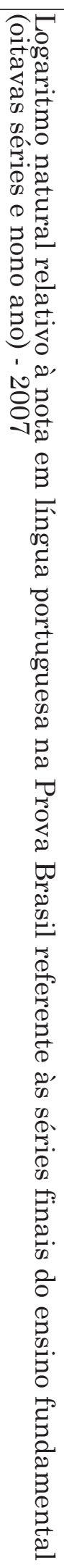 & 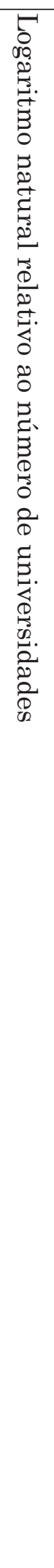 & 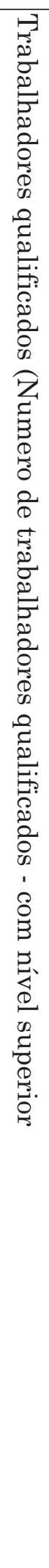 & 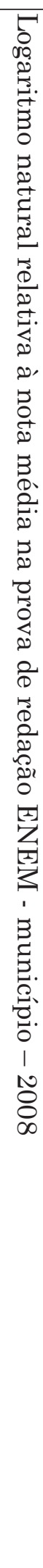 & 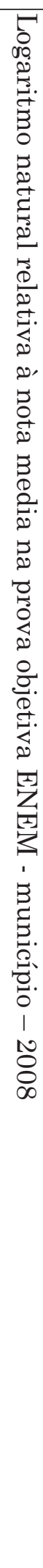 & 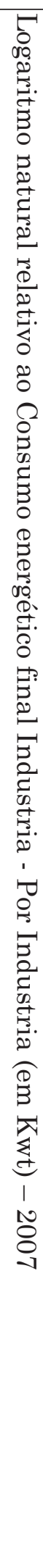 & 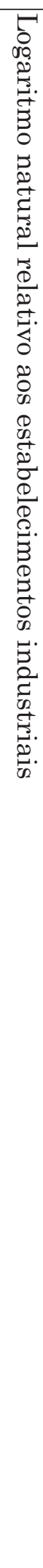 & 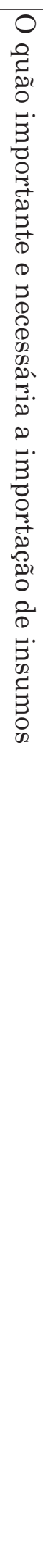 & 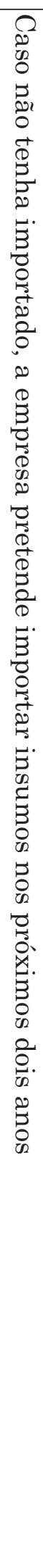 \\
\hline$\stackrel{\circ}{\ominus}$ & $\begin{array}{l}0 \\
0 \\
0 \\
-10\end{array}$ & $\begin{array}{l}0 \\
\infty \\
\infty \\
\infty\end{array}$ & $\begin{array}{l}0 \\
\infty \\
\infty \\
\mathbb{1}\end{array}$ & $\begin{array}{l}0 \\
\infty \\
\infty \\
\infty\end{array}$ & $\begin{array}{l}\circ \\
0 \\
\bullet\end{array}$ & $\begin{array}{l}0 \\
\infty \\
0 \\
0\end{array}$ & $\begin{array}{l}0 \\
8 \\
8 \\
8\end{array}$ & $\begin{array}{l}0 \\
\text { 기 } \\
\text { or }\end{array}$ & $\begin{array}{l}0 \\
\infty \\
1 \\
0\end{array}$ & 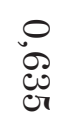 & $\begin{array}{l}0 \\
\infty \\
\infty \\
\text { D }\end{array}$ & $\begin{array}{l}0 \\
0 \\
0\end{array}$ & $\begin{array}{l}0 \\
0 \\
0 \\
-1\end{array}$ \\
\hline
\end{tabular}


Dimensões latentes da competitividade da micro e pequena indústria de transformação ...

\begin{tabular}{|c|c|c|c|c|c|c|c|c|c|c|c|c|}
\hline 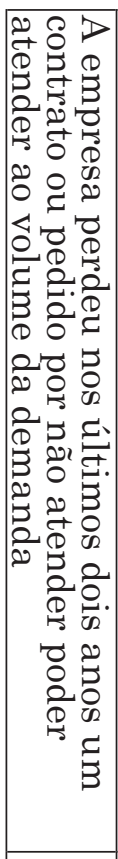 & 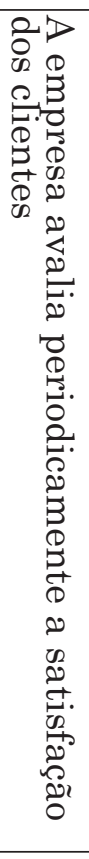 & 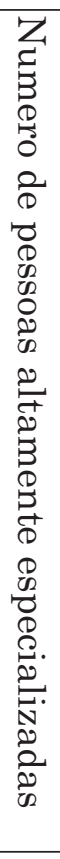 & 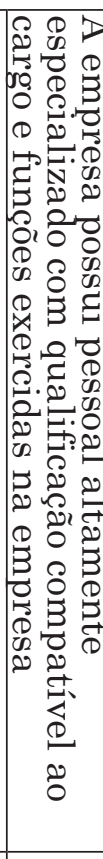 & 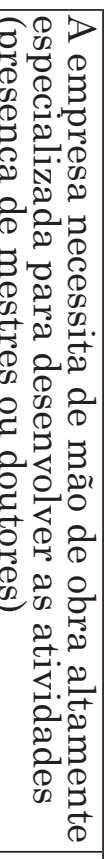 & 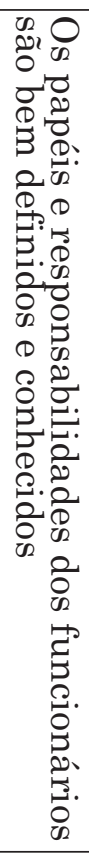 & 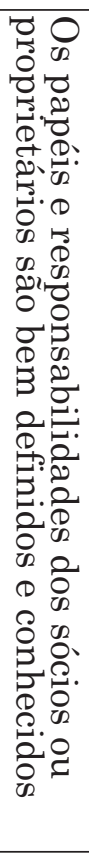 & 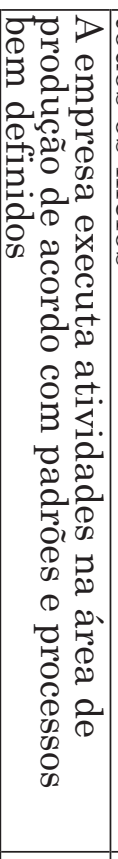 & 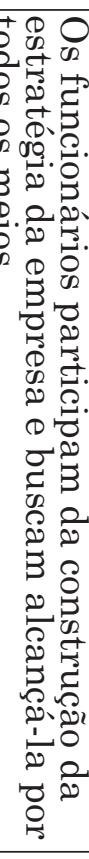 & 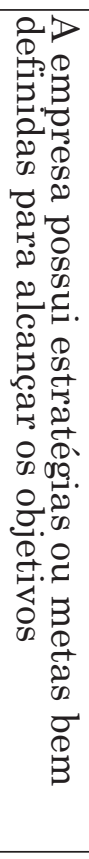 & 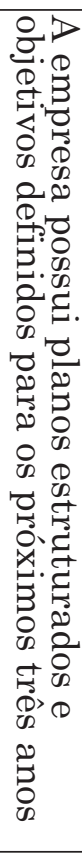 & & \\
\hline $\begin{array}{l}\stackrel{8}{\infty} \\
\infty \\
\infty\end{array}$ & $\stackrel{\infty}{\infty}$ & $\stackrel{\circ}{\stackrel{\circ}{N}}$ & $\begin{array}{l}\text { 음 } \\
\text { oै }\end{array}$ & ஜ & $\begin{array}{l}\text { ○े } \\
\text { N } \\
\end{array}$ & $\begin{array}{l}0 \\
\text { రิ } \\
0\end{array}$ & 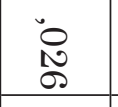 & $\begin{array}{l}\stackrel{\circ}{\oplus} \\
\text { cot }\end{array}$ & $\begin{array}{l}0 \\
\text { Do } \\
\text { Du }\end{array}$ & 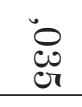 & $\vdash$ & \\
\hline $\begin{array}{l}\infty \\
\infty \\
\end{array}$ & 옹 & $\begin{array}{l}8 \\
\&\end{array}$ & $\begin{array}{l}\text { iv } \\
\text { \& }\end{array}$ & $\begin{array}{l}\infty \\
\infty \\
\infty\end{array}$ & 。ㅇํㄱ & $\begin{array}{l}\text { O̊ } \\
\text { er }\end{array}$ & $\begin{array}{l}0 \\
\text { N̦ } \\
\end{array}$ & $\begin{array}{l}\text { iv } \\
\text { d. } \\
\text { S }\end{array}$ & $\begin{array}{l}\text { No } \\
\text { S }\end{array}$ & $\begin{array}{l}\text { iv } \\
\infty \\
0 \\
\end{array}$ & $N$ & \\
\hline $\begin{array}{l}0 \\
\text { of } \\
\text { or }\end{array}$ & 芦 & $\begin{array}{l}\text { No } \\
\infty \\
\infty\end{array}$ & $\begin{array}{l}\text { iv } \\
\text { vi }\end{array}$ & $\begin{array}{l}\text { స̃ } \\
\stackrel{\leftrightarrow}{0}\end{array}$ & 光 & 词 & 苂 & $\stackrel{\vec{t}}{0}$ & $\stackrel{\sqrt[N]{ }}{\mathrm{v}}$ & $\stackrel{\vec{A}}{\vec{A}}$ & co & \\
\hline$\stackrel{1}{0}$ & 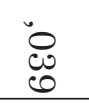 & 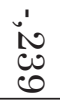 & $\begin{array}{l}\text { No } \\
\text { Or } \\
\text { or }\end{array}$ & ¿̊ & co & 占 & $\begin{array}{l}\text { O } \\
\text { ㅇ } \\
\end{array}$ & 莒 & $\begin{array}{l}\stackrel{\sim}{u} \\
\infty \\
\infty\end{array}$ & $\begin{array}{l}0 \\
\infty \\
0 \\
0\end{array}$ & 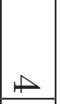 & \\
\hline 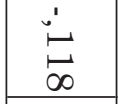 & $\stackrel{\mathscr{D}_{\infty}}{ }$ & $\stackrel{\mathscr{D}_{\infty}}{\infty}$ & $\stackrel{\infty}{\infty}$ & $\begin{array}{l}\text { No } \\
\text { N } \\
\text { S }\end{array}$ & 금 & $\begin{array}{l}\text { iv } \\
\infty\end{array}$ & $\stackrel{\circ}{\circ}$ & $\stackrel{\vec{\omega}}{\bullet}$ & बु & गु & or & \\
\hline 恖 & $\stackrel{\circ}{\circ}$ & 8 & 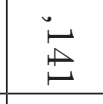 & 范 & $\begin{array}{l}0 \\
0 \\
01\end{array}$ & $\stackrel{0}{0}$ & $\begin{array}{l}0 \\
10 \\
1 \\
\end{array}$ & $\begin{array}{l}8 \\
1\end{array}$ & $\stackrel{\circ}{8}$ & 占 & $\sigma$ & \\
\hline 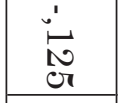 & 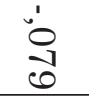 & $\begin{array}{l}\text { Sి } \\
\infty \\
\infty\end{array}$ & $\begin{array}{l}\text { os } \\
\text { y }\end{array}$ & 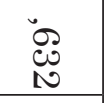 & $\stackrel{\vec{H}}{\vec{D}}$ & $\stackrel{\vec{\sigma}}{\sigma^{\prime}}$ & $\stackrel{ }{\circ}$ & $\begin{array}{l}\text { No } \\
\text { No } \\
\text { do }\end{array}$ & $\begin{array}{l}\text { N } \\
\stackrel{A}{\circ}\end{array}$ & $\begin{array}{l}\text { No } \\
\stackrel{N}{N}\end{array}$ & $\checkmark$ & $\frac{8}{3}$ \\
\hline 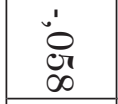 & $\begin{array}{l}{ }_{\infty}^{\prime} \\
\stackrel{\infty}{\infty}\end{array}$ & 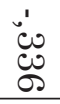 & 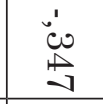 & $\begin{array}{l}1 \\
\text { Oे } \\
0\end{array}$ & $\begin{array}{l}1 \\
\infty \\
\infty\end{array}$ & $\begin{array}{l}1 \\
. \\
0 \\
0 \\
0\end{array}$ & $\ddot{8}$ & 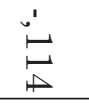 & $\begin{array}{l}1 \\
n_{N}^{\prime} \\
\text { N }\end{array}$ & 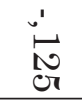 & $\infty$ & 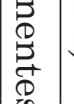 \\
\hline $\begin{array}{l}0 \\
0 \\
1 \\
1\end{array}$ & $\stackrel{\omega_{\omega}}{\omega_{0}}$ & 范 & 惢 & $\begin{array}{l}\circ \\
\text { 心 } \\
\text { o }\end{array}$ & $\begin{array}{l}\tilde{c}_{0} \\
\infty \\
0 \\
\end{array}$ & $\begin{array}{l}\text { co } \\
\text { C) }\end{array}$ & ¿ू. & $\stackrel{\circ}{\circ}$ & 党 & $\begin{array}{l}\dot{b}_{0}^{\prime} \\
\infty\end{array}$ & 0 & \\
\hline $\begin{array}{l}0 \\
1 \\
\infty\end{array}$ & $\begin{array}{l}\text { No } \\
\text { ᄋ }\end{array}$ & $\begin{array}{l}0 \\
1 \\
\infty \\
\infty\end{array}$ & $\begin{array}{l}\text { 엄 } \\
\text { ज. }\end{array}$ & $\underset{\infty}{\infty}$ & $\underset{\Delta}{\stackrel{\oplus}{\Delta}}$ & $\begin{array}{l}\text { S } \\
\text { N̦ }\end{array}$ & $\begin{array}{l}\odot \\
\infty \\
\end{array}$ & 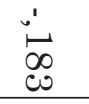 & $\begin{array}{l}\dot{\sigma}^{\prime} \\
\stackrel{\infty}{v}\end{array}$ & ثે & $\varpi$ & \\
\hline 这 & ¿.0 & 当 & ¿ & 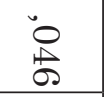 & $\sqrt{0}$ & $\begin{array}{l}\text { N } \\
\text { A }\end{array}$ & $\stackrel{\circ}{\stackrel{1}{N}}$ & 芦 & $\begin{array}{l}\stackrel{0}{ \pm} \\
\stackrel{y}{7}\end{array}$ & $\begin{array}{l}\text { OD } \\
\text { of }\end{array}$ & 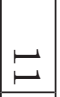 & \\
\hline 恕 & $\begin{array}{l}\bigodot_{\infty} \\
\infty \\
\infty\end{array}$ & $\begin{array}{l}8 \\
\end{array}$ & $\begin{array}{l}\stackrel{0}{1} \\
\stackrel{1}{A}\end{array}$ & $\begin{array}{l}\stackrel{\circ}{\circ} \\
\text { OI }\end{array}$ & 光 & $\begin{array}{l}\text { No } \\
\stackrel{1}{\circ}\end{array}$ & $\begin{array}{l}\text { No } \\
\text { ON }\end{array}$ & స̃. & $\begin{array}{l}\stackrel{\circ}{\circ} \\
\stackrel{1}{A}\end{array}$ & $\stackrel{\infty}{\infty}^{\prime}$ & N & \\
\hline $\begin{array}{l}0 \\
\infty \\
\infty\end{array}$ & ஓ & $\underset{\perp}{8}$ & $\begin{array}{l}8 \\
\stackrel{0}{0} \\
.0\end{array}$ & $\begin{array}{l}\circ \\
\infty \\
\infty \\
0\end{array}$ & $\begin{array}{l}\breve{0} \\
\dot{0}\end{array}$ & $\stackrel{\vec{D}}{0}$ & हु & $\begin{array}{l}\stackrel{\circ}{\circ} \\
\infty\end{array}$ & $\begin{array}{l}\circ \\
\infty \\
\infty \\
\infty\end{array}$ & $\begin{array}{l}8 \\
10 \\
1\end{array}$ & $\vec{\omega}$ & \\
\hline$\ddot{0}$ & $\begin{array}{l}0 \\
0 \\
0\end{array}$ & $\begin{array}{l}\circ \\
\stackrel{B}{\infty}\end{array}$ & 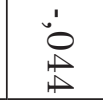 & $\stackrel{8}{8}$ & $\stackrel{-}{\circ}$ & $\stackrel{\mathbb{N}}{\mathrm{N}}$ & $\begin{array}{l}\text { "ृ) } \\
\text { gू }\end{array}$ & 官 & $\begin{array}{l}\ddot{0} \\
\stackrel{0}{\ominus}\end{array}$ & $\begin{array}{l}\circ \\
\text { ᄋ } \\
\stackrel{1}{1}\end{array}$ & $\vec{\Delta}$ & \\
\hline
\end{tabular}




\begin{tabular}{|c|c|c|c|c|c|c|c|c|c|c|c|c|c|c|}
\hline 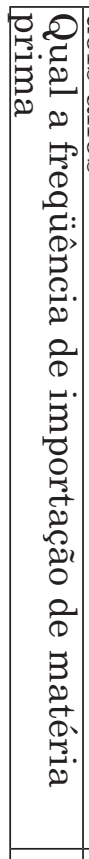 & 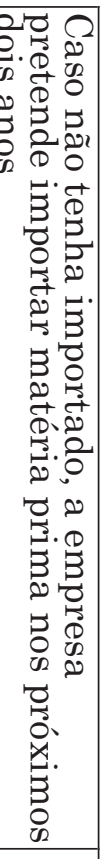 & 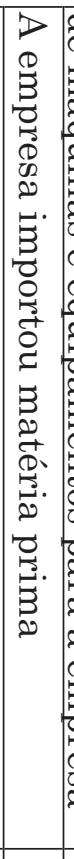 & 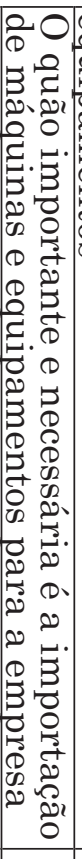 & 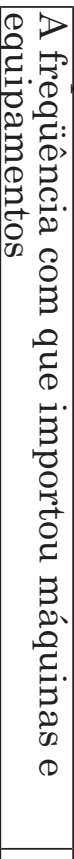 & 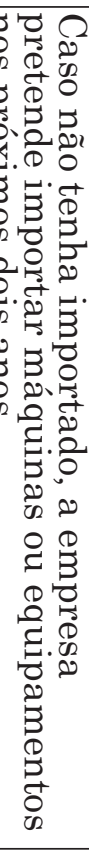 & 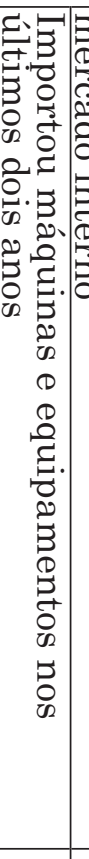 & 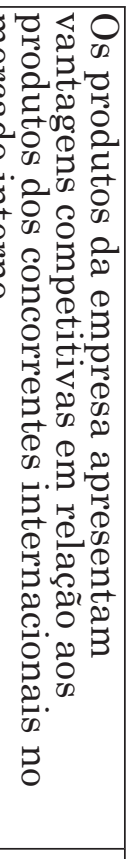 & 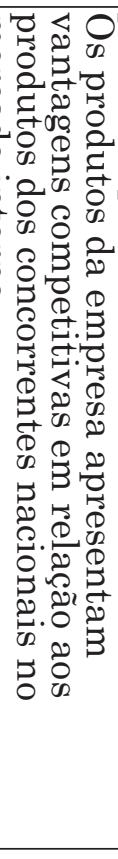 & 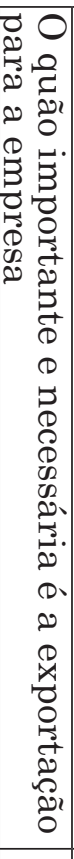 & 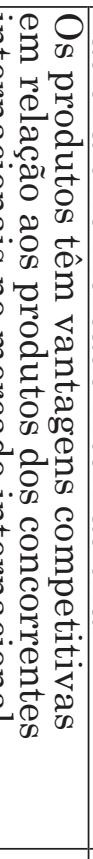 & 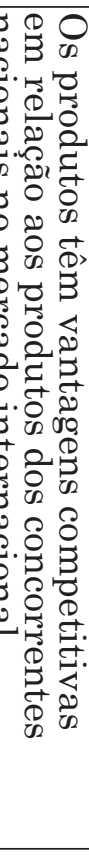 & 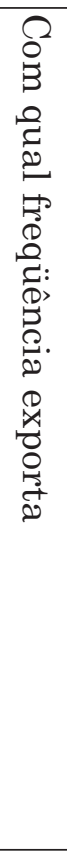 & 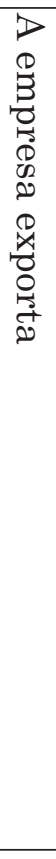 & 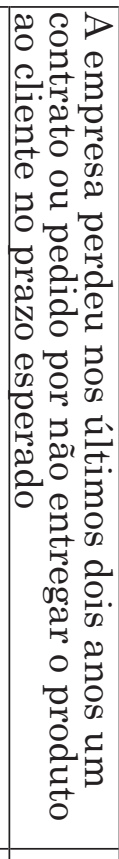 \\
\hline 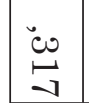 & $\begin{array}{l}\text { '0 } \\
\text { 건 }\end{array}$ & $\begin{array}{l}\text { iv } \\
\text { co }\end{array}$ & 迆 & $\begin{array}{l}\circ \\
\\
\end{array}$ & ஓ & $\ddot{\circ}$ & 吕 & '̊ & ஜ̈ & 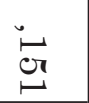 & 点 & 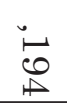 & 苞 & ช్ \\
\hline $\begin{array}{l}\text { No } \\
\text { ơ }\end{array}$ & 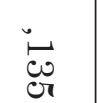 & 苍 & 芦 & ஸั & $\begin{array}{l}1 \\
0 \\
\infty \\
\infty\end{array}$ & 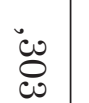 & $\begin{array}{l}\text { N. } \\
\text { N }\end{array}$ & $\stackrel{\circ}{\circ}$ & 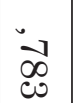 & Uु & $\stackrel{\infty}{\infty}$ & రె & 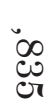 & 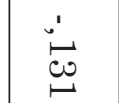 \\
\hline or & '̊ & 总 & 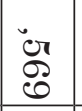 & 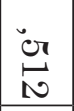 & 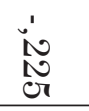 & 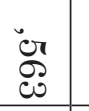 & $\stackrel{\infty}{\infty}$ & ஓ & s & 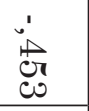 & $\frac{1}{1}$ & $\stackrel{\text { 点 }}{\stackrel{\prime}{口}}$ & 若 & '̊. \\
\hline $\begin{array}{l}\bullet \\
\varnothing\end{array}$ & $\begin{array}{l}\stackrel{0}{\ominus} \\
\stackrel{\omega}{\omega}\end{array}$ & 芦 & $\begin{array}{l}\text { in } \\
\text { D } \\
\end{array}$ & 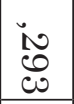 & $\stackrel{\prime}{\circ}$ & 岂 & 苞 & $\stackrel{\bullet}{\stackrel{*}{*}}$ & 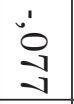 & $\begin{array}{l}1 \\
\infty \\
\infty \\
\infty \\
\infty\end{array}$ & 。 & 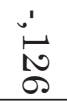 & م' & $\begin{array}{l}1 \\
\\
\text { N } \\
\end{array}$ \\
\hline $\begin{array}{l}\text { No } \\
\text { O }\end{array}$ & 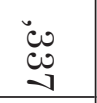 & 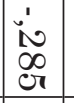 & $\begin{array}{l}1 \\
\infty \\
\infty \\
\infty\end{array}$ & $\begin{array}{l}\dot{1} \\
\stackrel{1}{1} \\
\stackrel{1}{\perp}\end{array}$ & $\begin{array}{l}\text { No } \\
\text { O }\end{array}$ & $\begin{array}{l}\text { '0 } \\
\text { 겅 }\end{array}$ & $\stackrel{\circ}{\circ}$ & 今 & $\stackrel{8}{8}$ & $\begin{array}{l}\stackrel{H}{N}^{\prime} \\
\mathscr{\sigma}\end{array}$ & $\begin{array}{l}0 \\
\infty \\
0 \\
\text { or }\end{array}$ & $\stackrel{.}{\stackrel{N}{N}}$ & 。 & $\begin{array}{l}\text { ¿ㅇ } \\
\text { 이 }\end{array}$ \\
\hline 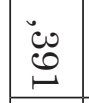 & ث̊. & 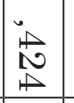 & 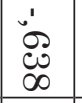 & ڤ్త & $\begin{array}{l}\text { co } \\
\text { d. }\end{array}$ & $\begin{array}{l}\text { s. } \\
\text { s. }\end{array}$ & 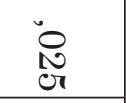 & 节 & న్ & 'ீ & $\stackrel{\circ}{\stackrel{1}{*}}$ & '̊ & 。ُ & $\stackrel{1}{\stackrel{0}{J}}$ \\
\hline مِّ & 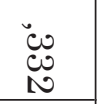 & 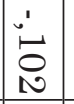 & $\begin{array}{l}0 \\
0 \\
N \\
1\end{array}$ & $\begin{array}{l}\circ \\
\text { ᄋ్ } \\
\infty\end{array}$ & 污 & $\begin{array}{l}\stackrel{\circ}{\circledR} \\
\stackrel{1}{\mapsto}\end{array}$ & 苛 & 峁 & ○̊ & 官 & ஜீ & $\begin{array}{l}\dot{\circ} \\
\stackrel{1}{N}\end{array}$ & '̊요 & 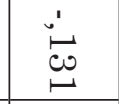 \\
\hline 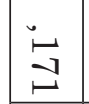 & ஜ) & 芦 & $\begin{array}{l}\stackrel{\circ}{\circ} \\
\stackrel{\vec{D}}{ }\end{array}$ & $\begin{array}{l}\stackrel{0}{0} \\
\text { No }\end{array}$ & $\begin{array}{l}\text { "r } \\
\infty \\
0\end{array}$ & ¿̊. & 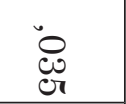 & $\begin{array}{l}\text { ○् } \\
\text { or }\end{array}$ & $\stackrel{\circ}{\ominus}$ & '̊ & 官 & $\stackrel{\mathscr{C}}{\ominus}$ & $\stackrel{\circ}{\stackrel{\circ}{0}}$ & $\stackrel{\omega}{\omega}_{\infty}^{\prime}$ \\
\hline 足 & $\begin{array}{l}\stackrel{1}{\circ} \\
\stackrel{9}{y}\end{array}$ & $\begin{array}{l}1 \\
\infty \\
\infty \\
1 \\
1\end{array}$ & 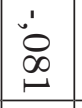 & 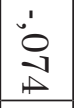 & $\begin{array}{l}0 \\
\text { or } \\
\text { or }\end{array}$ & 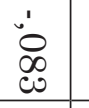 & 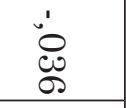 & $\begin{array}{l}0 \\
\text { o } \\
\text { ō }\end{array}$ & ○̊ & $\begin{array}{l}0 \\
\text { ำ }\end{array}$ & ర్ల & $\begin{array}{l}\infty \\
\infty \\
\infty \\
\end{array}$ & 용 & 苛 \\
\hline ஜ용 & 。 & 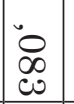 & $\stackrel{.}{\circ}$ & $\dot{8}$ & ஜ) & ○ & $\begin{array}{l}\circ \\
\text { 응 }\end{array}$ & $\stackrel{N}{\stackrel{N}{ت}}$ & $\stackrel{0}{\circ}$ & ¿̊ำ & 읍 & 8 & بـ & ن̊ \\
\hline $\begin{array}{l}\text { iv } \\
\text { ¿̦ }\end{array}$ & $\begin{array}{l}\stackrel{1}{\circ} \\
\stackrel{-}{\ominus}\end{array}$ & $\begin{array}{l}\text { N. } \\
\text { N } \\
\text { O }\end{array}$ & 官 & $\stackrel{\circ}{\circ}$ & $\stackrel{\circ}{\circ}$ & 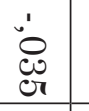 & $\begin{array}{l}1 \\
\stackrel{1}{*} \\
\end{array}$ & $\begin{array}{l}\stackrel{\circ}{0}^{\prime} \\
\text { or }\end{array}$ & $\begin{array}{l}\stackrel{0}{\circ} \\
\text { er }\end{array}$ & : & 。용 & 8 & $\begin{array}{l}8 \\
8 \\
\end{array}$ & "ृ \\
\hline ') & \&্ & 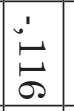 & $\stackrel{\circ}{\ominus}$ & $\begin{array}{l}1 \\
\text { ' } \\
\text { N } \\
\end{array}$ & $\begin{array}{l}\stackrel{0}{\circ} \\
\stackrel{0}{\omega}\end{array}$ & 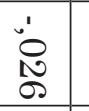 & $\begin{array}{l}\mathscr{D}_{\infty} \\
\text { d. }\end{array}$ & $\stackrel{\stackrel{\bullet}{J}}{\square}$ & 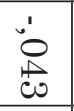 & $\begin{array}{l}\stackrel{\infty}{\infty} \\
\stackrel{\infty}{\perp}\end{array}$ & '̊ & 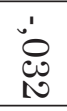 & '̊ & $\begin{array}{l}\text { iv } \\
\text { co } \\
\text { Con }\end{array}$ \\
\hline 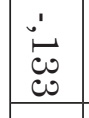 & 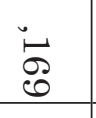 & $\begin{array}{l}\dot{u} \\
\dot{\sigma} \\
\sigma \\
\sigma\end{array}$ & $\begin{array}{l}\circ \\
\stackrel{0}{\ominus} \\
\end{array}$ & $\begin{array}{l}1 \\
\\
\end{array}$ & 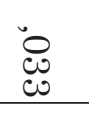 & $\begin{array}{l}\text { ○े } \\
\text { or }\end{array}$ & $\begin{array}{l}\tilde{c}_{0} \\
\infty \\
\infty \\
\Omega\end{array}$ & 巳o & $\stackrel{\circ}{\stackrel{\circ}{\ominus}}$ & ¿̊ & 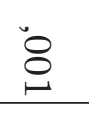 & $\begin{array}{l}\text { O } \\
\text { N. } \\
\text { Non }\end{array}$ & & $\begin{array}{l}\text { co } \\
\text { er }\end{array}$ \\
\hline 官 & 'י & $\begin{array}{l}1 \\
\stackrel{1}{\circ} \\
\end{array}$ & 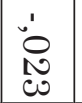 & $\begin{array}{l}1 \\
\text { '̊ } \\
\text { N. }\end{array}$ & 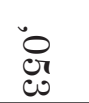 & $\begin{array}{l}1 \\
\stackrel{1}{\circ} \\
\text { No }\end{array}$ & $\begin{array}{l}\text { iv } \\
\text { Oٓ }\end{array}$ & 긍 & $\begin{array}{l}\stackrel{\circ}{\circ} \\
\stackrel{\vec{b}}{\circ}\end{array}$ & $\begin{array}{l}\stackrel{1}{\circ} \\
\stackrel{1}{N}\end{array}$ & $\begin{array}{l}\dot{0} \\
\stackrel{0}{0} \\
ن\end{array}$ & $\begin{array}{l}\dot{0} \\
\stackrel{0}{0}\end{array}$ & $\begin{array}{l}0 \\
\text { No } \\
\text { con }\end{array}$ & $\begin{array}{l}\text { 임 } \\
\text { ō }\end{array}$ \\
\hline
\end{tabular}


Dimensões latentes da competitividade da micro e pequena indústria de transformação ...

\begin{tabular}{|c|c|c|c|c|c|c|c|c|c|}
\hline 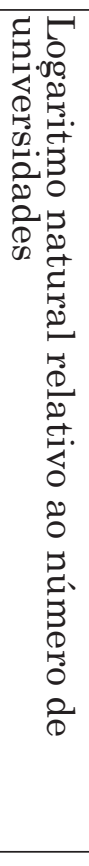 & 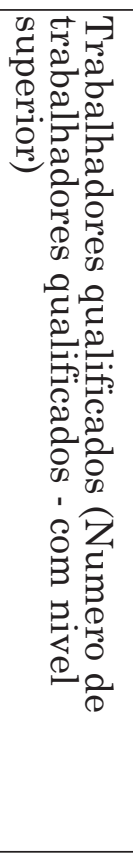 & 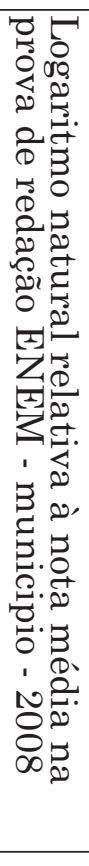 & 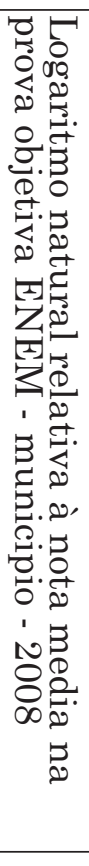 & 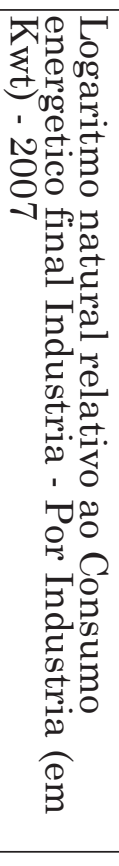 & 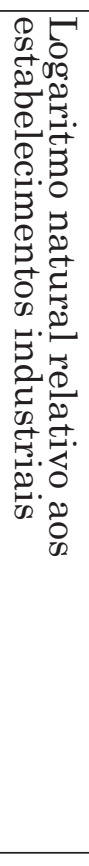 & 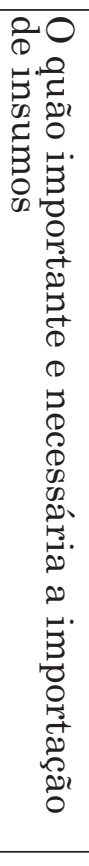 & 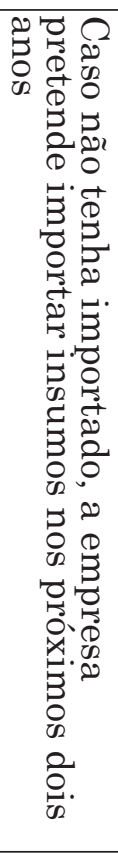 & $\begin{array}{l}D \\
D \\
0 \\
3 \\
3 \\
0 \\
0 \\
0 \\
0 \\
0 \\
5 \\
5 \\
3 \\
0 \\
0 \\
5 \\
0 \\
0 \\
5 \\
0 \\
0 \\
5 \\
5 \\
0 \\
0\end{array}$ & 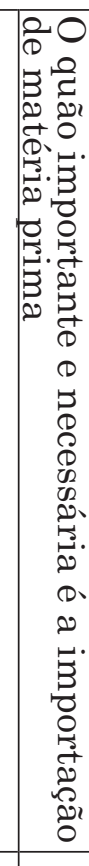 \\
\hline $\begin{array}{l}\text { 㕷 } \\
\end{array}$ & $\begin{array}{l}\infty \\
N \\
N \\
\end{array}$ & $\begin{array}{l}\text { iv } \\
\stackrel{1}{0}\end{array}$ & $\stackrel{\stackrel{i}{*}}{\stackrel{i}{*}}$ & $\begin{array}{l}\text { iv } \\
\infty \\
\text { - }\end{array}$ & ' & $\stackrel{\text { No }}{\stackrel{N}{*}}$ & 8 & ¿ & 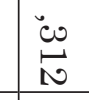 \\
\hline $\begin{array}{l}\text { No } \\
\text { N } \\
\text { - }\end{array}$ & 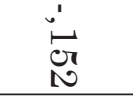 & ஓ & $\stackrel{\omega}{\omega}$ & $\begin{array}{l}\text { iv } \\
\text { d. } \\
\sigma\end{array}$ & $\%$ & 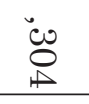 & $\begin{array}{l}\mathscr{C}_{0} \\
\stackrel{A}{A}\end{array}$ & 苛 & $\begin{array}{l}\text { iv } \\
\text { ¿ } \\
\infty\end{array}$ \\
\hline 官 & $\begin{array}{l}0 \\
\text { 언 } \\
\end{array}$ & 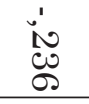 & $\begin{array}{l}\text { No } \\
\text { जै }\end{array}$ & ب0 & 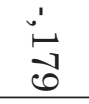 & or & $\begin{array}{l}0 \\
0\end{array}$ & $\begin{array}{l}\text { or } \\
\text { er }\end{array}$ & $\begin{array}{l}\text { os } \\
\text { ? }\end{array}$ \\
\hline $\begin{array}{l}\stackrel{\prime}{\circ} \\
\stackrel{\ominus}{v}\end{array}$ & $\begin{array}{l}\dot{c} \\
\stackrel{c}{\infty} \\
\infty\end{array}$ & రి & $\begin{array}{l}\circ \\
\infty \\
\infty \\
\infty\end{array}$ & $\underset{\infty}{\stackrel{\infty}{\infty}}$ & 当 & 8 & $\begin{array}{l}\infty \\
\infty \\
0 \\
0\end{array}$ & تُ & ڤัo \\
\hline $\begin{array}{l}\text { \& } \\
\text { \& }\end{array}$ & $\begin{array}{l}\infty \\
\infty \\
\infty\end{array}$ & 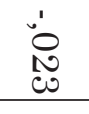 & $\begin{array}{l}\stackrel{1}{\circ} \\
\text { cor }\end{array}$ & 。용 & வ & $\stackrel{i}{\stackrel{N}{N}}$ & $\begin{array}{l}\text { iv } \\
\stackrel{D}{\perp}\end{array}$ & 点 & $\begin{array}{l}\stackrel{1}{1} \\
\infty \\
\infty\end{array}$ \\
\hline $\begin{array}{l}\dot{\circ} \\
\stackrel{\circ}{\circ}\end{array}$ & $\begin{array}{l}0 \\
\mathscr{S} \\
\sigma\end{array}$ & $\begin{array}{l}\stackrel{N}{N} \\
\infty\end{array}$ & $\begin{array}{l}\mathfrak{\omega}_{0} \\
\tilde{c}_{0}\end{array}$ & 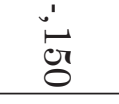 & ஓ & $\begin{array}{l}\infty \\
\infty \\
\infty \\
\infty\end{array}$ & $\begin{array}{l}0 \\
\varnothing 0 \\
10\end{array}$ & $\stackrel{\text { ¿ }}{\stackrel{\rho}{\ominus}}$ & $\begin{array}{l}0.0 \\
0 \\
\end{array}$ \\
\hline $\begin{array}{l}\stackrel{0}{6} \\
\qquad\end{array}$ & $\begin{array}{l}1 \\
\circ \\
\stackrel{\circ}{\circ}\end{array}$ & $\begin{array}{l}\text { No } \\
\text { con }\end{array}$ & 苞 & 용 & ஓ & $\begin{array}{l}\text { ○ิ } \\
\text { N }\end{array}$ & 造 & $\begin{array}{l}0 \\
\mathbb{N} \\
\infty\end{array}$ & 今. \\
\hline$\stackrel{8}{\infty}$ & ○ & 잉 & $\begin{array}{l}1 \\
\infty \\
\infty \\
0 \\
0\end{array}$ & $\stackrel{\infty}{\infty}$ & $\begin{array}{l}0 \\
\text { N } \\
\text { N }\end{array}$ & $\begin{array}{l}0 \\
\infty \\
\infty \\
\infty\end{array}$ & ब্. & $\begin{array}{l}0 \\
\infty \\
0 \\
0\end{array}$ & 㐾 \\
\hline ¿̊ & $\begin{array}{l}\text { No } \\
\infty \\
\infty\end{array}$ & 巨 & $\stackrel{\ominus}{\circ}^{\prime}$ & $\begin{array}{l}\text { er } \\
\stackrel{\Delta}{\infty} \\
\end{array}$ & $\begin{array}{l}\stackrel{0}{\infty} \\
\stackrel{D}{\perp}\end{array}$ & 。 & 응 & Ґু & $\begin{array}{l}1 \\
\infty \\
-1 \\
-1\end{array}$ \\
\hline $\begin{array}{l}\stackrel{\circ}{\sigma} \\
\stackrel{\sigma}{\sigma}\end{array}$ & $\begin{array}{l}\mathfrak{c o s}_{0} \\
\tilde{c}_{0}\end{array}$ & $\begin{array}{l}\text { o } \\
\text { or }\end{array}$ & $\begin{array}{l}8 \\
\stackrel{9}{1} \\
\end{array}$ & $\begin{array}{l}\stackrel{1}{N} \\
\stackrel{\mapsto}{\mapsto} \\
\end{array}$ & $\stackrel{\circ}{\circ}$ & 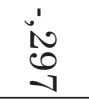 & $\begin{array}{l}\mathscr{\omega}_{0} \\
.0\end{array}$ & $\begin{array}{l}1 \\
\text { in } \\
\infty \\
0\end{array}$ & $\begin{array}{l}\circ \\
\text { oี }\end{array}$ \\
\hline 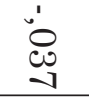 & $\stackrel{\circ}{\mathcal{1}}$ & $\begin{array}{l}\stackrel{0}{0} \\
\stackrel{+}{0}\end{array}$ & $\begin{array}{l}1 \\
\text { No } \\
\text { N }\end{array}$ & $\stackrel{\circ}{\circ}$ & 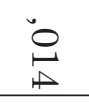 & $\stackrel{i}{e}$ & $\stackrel{\circ}{\circ}$ & 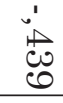 & $\begin{array}{l}\text { iv } \\
0 \\
0\end{array}$ \\
\hline 家 & \& & $\stackrel{\circ}{\circ}$ & $\begin{array}{l}\text { O } \\
\text { ᄋ }\end{array}$ & 㟔 & $\stackrel{8}{c}$ & స̃ & 움 & $\begin{array}{l}\text { iิ } \\
\end{array}$ & 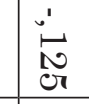 \\
\hline 8 & $\begin{array}{l}0 \\
\text { 읍 }\end{array}$ & $\begin{array}{l}\tilde{\omega}_{0} \\
\sigma\end{array}$ & 임 & $\stackrel{+}{\stackrel{N}{*}}$ & ¿ & 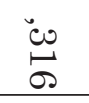 & 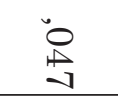 & 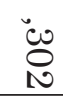 & 崩 \\
\hline$\stackrel{\circ}{\circ}$ & ஜ & $\stackrel{0}{\circ}$ & $\stackrel{\circ}{\circ}$ & 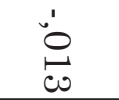 & $\stackrel{0}{\circ}$ & 戹 & 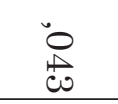 & $\begin{array}{l}\text { O } \\
\text { 菅 }\end{array}$ & $P$ \\
\hline
\end{tabular}


Flávio de Oliveira Gonçalves, Marco Túlio Aniceto França, Rodrigo Gomes Marques Silvestre

\begin{tabular}{|c|c|c|c|c|c|}
\hline 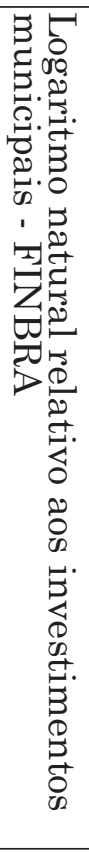 & 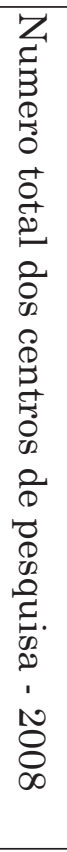 & 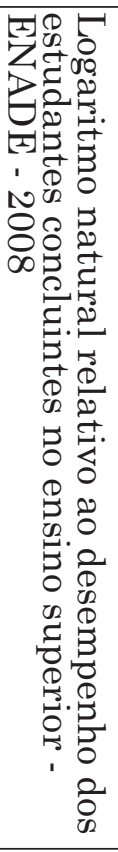 & 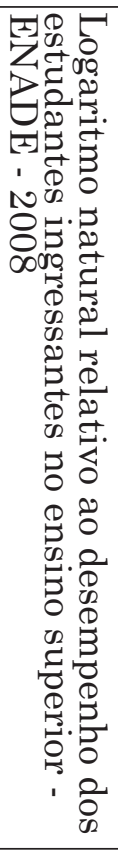 & 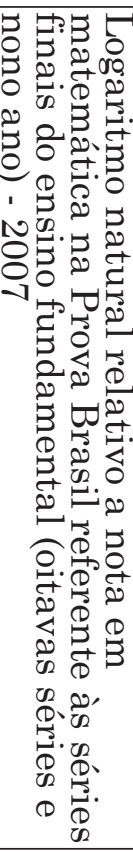 & 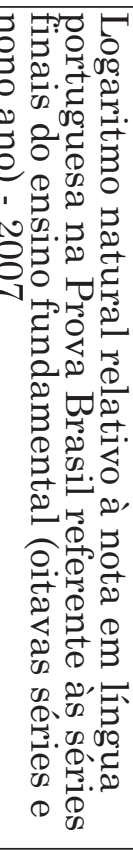 \\
\hline 긍 & कొ & 름 & oै & 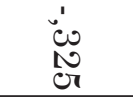 & 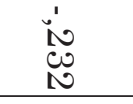 \\
\hline 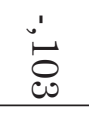 & $\stackrel{\circ}{尸}^{\prime}$ & $\begin{array}{l}\text { No } \\
\text { N } \\
\text { A }\end{array}$ & 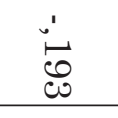 & $\begin{array}{l}0 \\
80 \\
00\end{array}$ & $\begin{array}{l}0 \\
\text { o } \\
\text { o }\end{array}$ \\
\hline$\stackrel{\stackrel{\prime}{\rightleftarrows}}{\stackrel{\leftrightarrow}{\rightleftarrows}}$ & 'ே & $\begin{array}{l}\check{O}^{\prime} \\
\infty \\
\infty\end{array}$ & 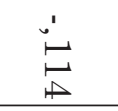 & $\begin{array}{l}\stackrel{\sigma}{\prime}^{\prime} \\
\stackrel{\infty}{\sigma}\end{array}$ & $\stackrel{\infty}{\stackrel{\infty}{*}}$ \\
\hline $\begin{array}{l}0_{0}^{0} \\
\infty \\
\infty\end{array}$ & $\begin{array}{l}\text { N̦ } \\
\text { Õ } \\
\text { N }\end{array}$ & 洸 & 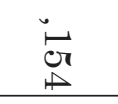 & जै & $\stackrel{\infty}{\stackrel{\infty}{v}}$ \\
\hline 号 & ๑̊ & $\begin{array}{l}0 \\
\infty \\
\infty\end{array}$ & $\begin{array}{l}0 \\
\text { ᄋ్ } \\
\infty\end{array}$ & 峁 & $\begin{array}{l}\mathfrak{n}^{\prime} \\
\stackrel{\omega}{\omega}\end{array}$ \\
\hline$\stackrel{\circ}{\circ}$ & 'ீ & ○ु & 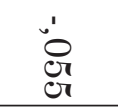 & 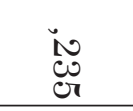 & $\begin{array}{l}\text { iv } \\
0 \\
\infty \\
\infty\end{array}$ \\
\hline $\begin{array}{l}\text { O } \\
\text { or }\end{array}$ & 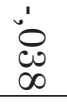 & 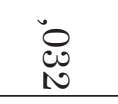 & \begin{tabular}{l}
0 \\
\hdashline 0 \\
0 \\
0
\end{tabular} & 。 & 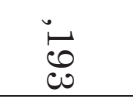 \\
\hline 吕 & $\stackrel{\circ}{\circ}$ & $\begin{array}{l}0 \\
0 \\
0\end{array}$ & $\begin{array}{l}0 \\
\text { O) } \\
\infty\end{array}$ & $\stackrel{N}{N}$ & 光 \\
\hline 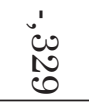 & 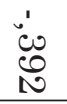 & $\begin{array}{l}\text { 惡 } \\
\text { N }\end{array}$ & is & 今' & $\begin{array}{l}1 \\
\text { '0 }\end{array}$ \\
\hline$\stackrel{\ddot{c}}{\ddot{D}}$ & $\begin{array}{l}\stackrel{\sigma}{\infty} \\
\infty \\
0 \\
0\end{array}$ & 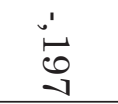 & $\begin{array}{l}\text { 'N } \\
\text { N. } \\
\text { O. }\end{array}$ & 官 & $\begin{array}{l}\dot{1} \\
\text { 囱 }\end{array}$ \\
\hline 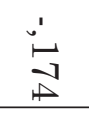 & 峁 & $\begin{array}{l}\stackrel{\circ}{\infty} \\
\stackrel{\infty}{\perp}\end{array}$ & $\begin{array}{l}\circ \\
\stackrel{\circ}{\circ} \\
\end{array}$ & 임 & 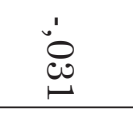 \\
\hline $\begin{array}{l}\stackrel{0}{0} \\
\text { de }\end{array}$ & $\begin{array}{l}\infty \\
\infty \\
\infty \\
\infty\end{array}$ & 8 & 光 & '̊ & \&̊) \\
\hline $\begin{array}{l}\text { ¿o } \\
\text { U. }\end{array}$ & $\begin{array}{l}0 \\
0 \\
0 \\
0\end{array}$ & $\begin{array}{l}0 \\
\end{array}$ & $\begin{array}{l}\text { ¿ी } \\
0\end{array}$ & 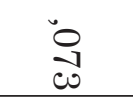 & ஜ \\
\hline$\stackrel{\circ}{\circ}$ & ஜே & $\begin{array}{l}0 \\
\text { ō }\end{array}$ & 苂 & $\begin{array}{l}\stackrel{0}{\circ} \\
\text { 官 }\end{array}$ & 弚 \\
\hline
\end{tabular}


Dimensões latentes da competitividade da micro e pequena indústria de transformação ...

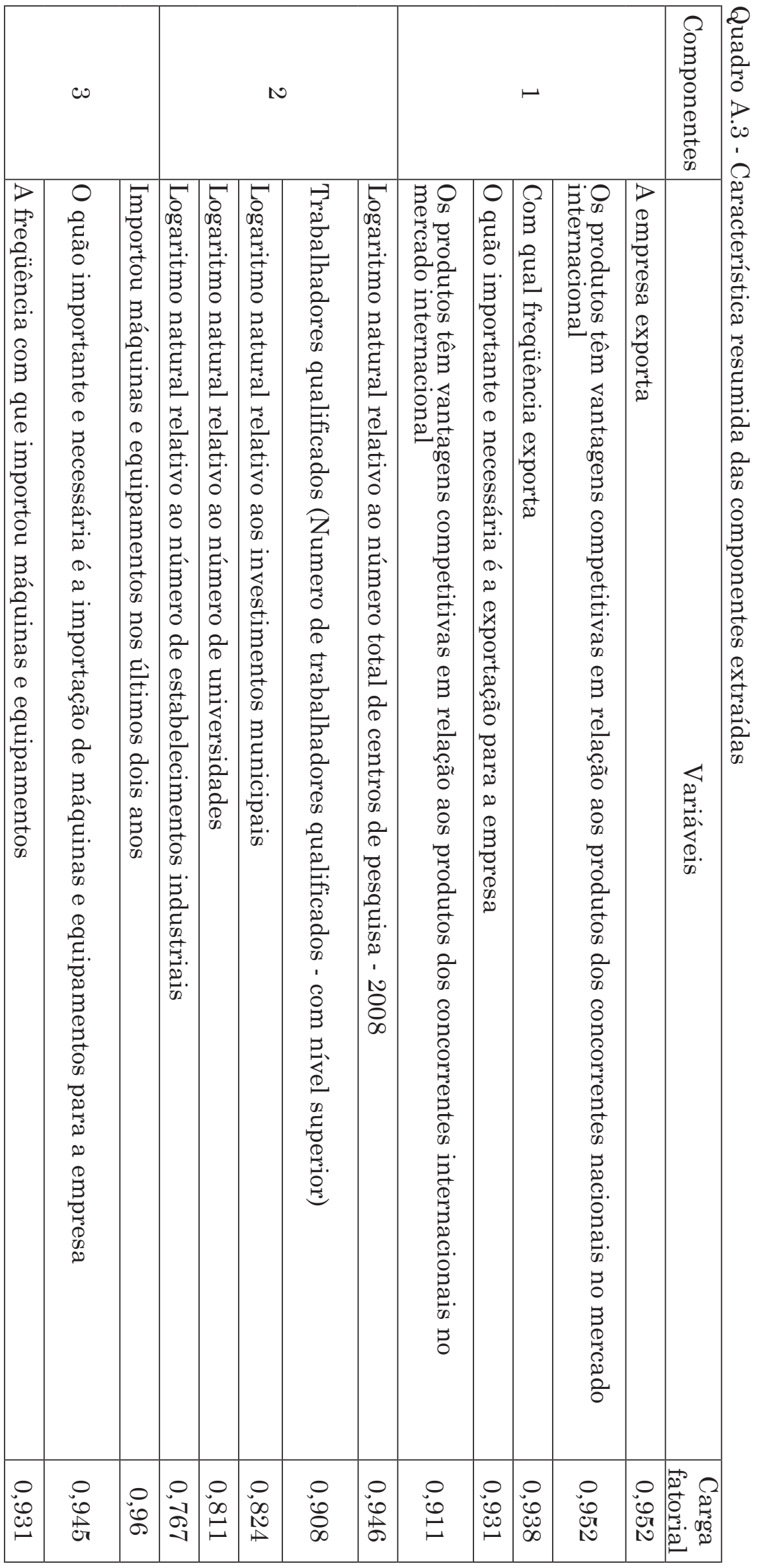




\begin{tabular}{|c|c|c|c|c|c|c|c|c|c|c|c|c|c|c|c|}
\hline \multicolumn{3}{|c|}{$\infty$} & \multicolumn{3}{|c|}{$\checkmark$} & \multicolumn{3}{|c|}{$\sigma$} & \multicolumn{3}{|c|}{ or } & \multicolumn{4}{|c|}{$A$} \\
\hline 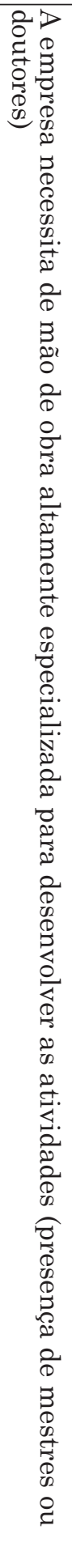 & 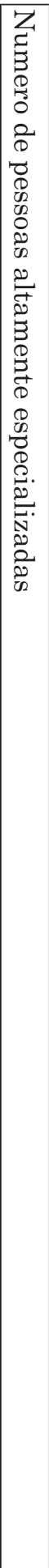 & 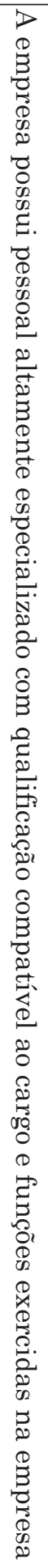 & 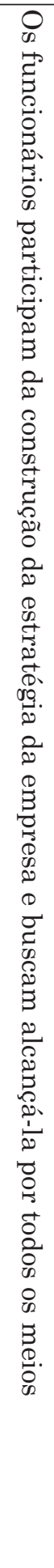 & 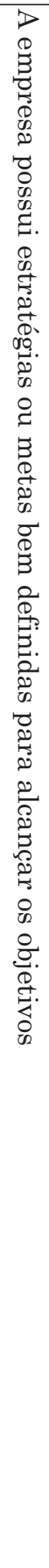 & 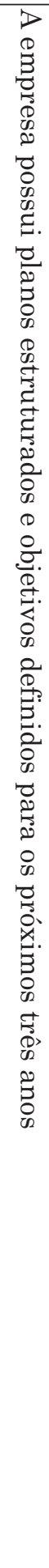 & 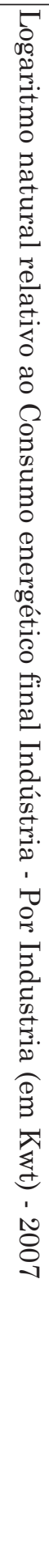 & 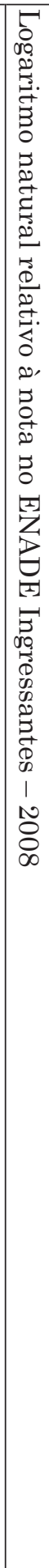 & 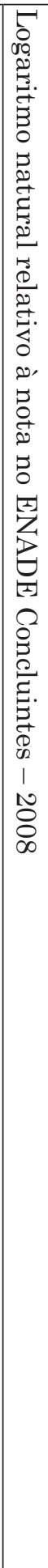 & 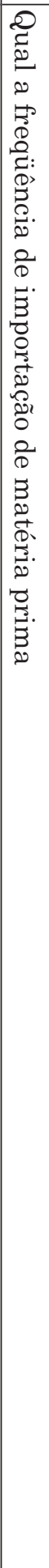 & 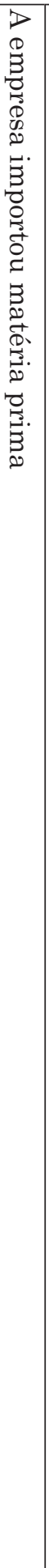 & 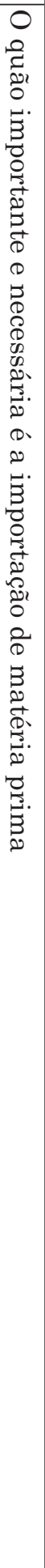 & 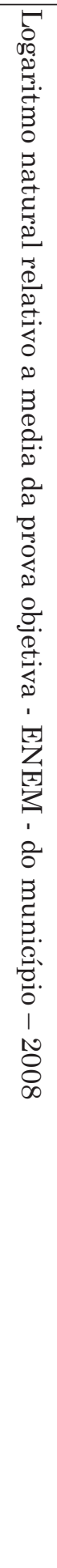 & 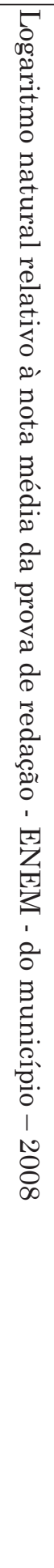 & 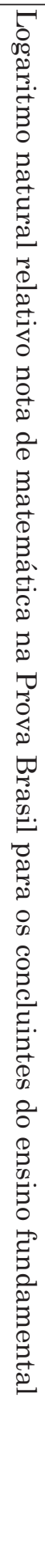 & 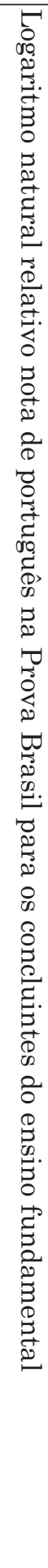 \\
\hline $\begin{array}{l}0 \\
\infty \\
\infty \\
\infty\end{array}$ & $\begin{array}{l}0 \\
\infty \\
\infty \\
\sigma \\
\sigma\end{array}$ & $\begin{array}{l}0 \\
0 \\
10\end{array}$ & $\begin{array}{l}0 \\
\infty \\
\infty \\
\infty \\
\infty\end{array}$ & $\begin{array}{l}0 \\
0 \\
\stackrel{0}{\sigma} \\
\sigma\end{array}$ & 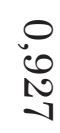 & $\begin{array}{l}0 \\
\text { Jै } \\
\text { 尸 }\end{array}$ & 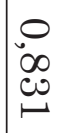 & $\begin{array}{l}0 \\
\infty \\
\infty \\
\mathbb{A}\end{array}$ & $\begin{array}{l}0 \\
0 \\
0 \\
\omega\end{array}$ & $\begin{array}{l}0 \\
0 \\
. \\
0 \\
0\end{array}$ & 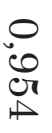 & $\begin{array}{l}0 \\
01 \\
0 \\
N\end{array}$ & $\begin{array}{l}0 \\
07 \\
0 \\
N\end{array}$ & $\begin{array}{l}\circ \\
\infty \\
\stackrel{\infty}{\bullet} \\
\stackrel{1}{*}\end{array}$ & $\begin{array}{l}0 \\
\text { o̊ } \\
8\end{array}$ \\
\hline
\end{tabular}


Dimensões latentes da competitividade da micro e pequena indústria de transformação ...

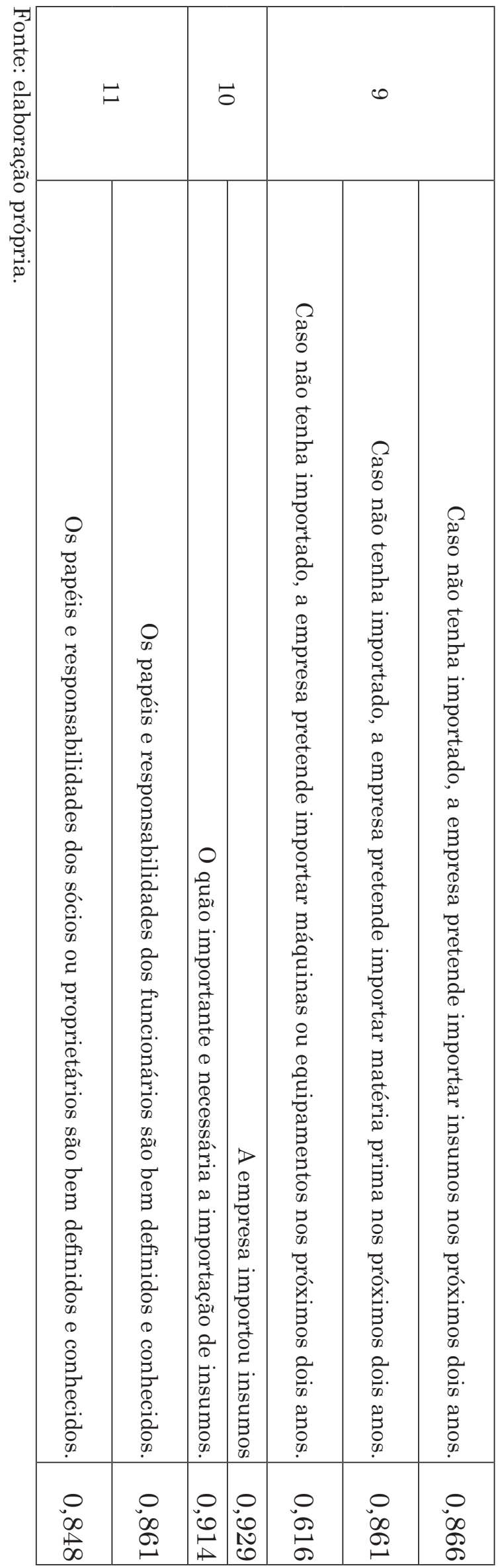


